\title{
Observed mean and mesoscale upper ocean circulation in the midlatitude northeast Atlantic
}

\author{
Bernard Le Cann $^{1 *}$, Michel Assembaum ${ }^{2}$, Jean-Claude Gascard ${ }^{3}$ \\ And Gilles Reverdin ${ }^{3}$
}

\author{
${ }^{1}$ Laboratoire de Physique des Océans, CNRS/IFREMER/UBO, UFR Sciences, 6 avenue Le Gorgeu, C.S. 93837 \\ 29238 Brest Cedex 3, France (Fax: 33298016468 , \\ ${ }^{2}$ LEGOS / BRESM, 14 avenue Edouard Belin, 31400 TOULOUSE France \\ ${ }^{3}$ LODYC, Univ. Paris VI, boîte 100, 4, place Jussieu, 75252 Paris Cedex 05, France \\ *: Corresponding author : email: blecann@univbrest.fr
}

\begin{abstract}
Lagrangian instruments and altimetry data are used to investigate the upper ( 0 to $\sim 500 \mathrm{~m}$ ) mean and mesoscale circulations in a region of the midlatitude northeast Atlantic $\left(36^{\circ}-47^{\circ} \mathrm{N}, 13^{\circ}-\right.$ $23^{\circ} \mathrm{W}$ ), a formation and subduction area of Subpolar Mode Water. Lagrangian data were collected between September 2000 and September 2001 with isobaric subsurface floats, totaling 34.0 float years, and surface drifting buoys, totaling 27.9 buoy years. The near-surface $(0-100 \mathrm{~m})$ mean circulation is dominated by two weak $(\sim 5 \mathrm{~cm} / \mathrm{s})$ eastward currents which veer southward in the domain. In the 100- to 500-m-deep layer, these eastward mean currents retroflect westward and form two anticyclonic circulation cells, opened to the west and separated by a cyclonic cell. Eddy kinetic energy is decreasing from the northwest to the southeast of the area, from $\sim 100-200(\mathrm{~cm} / \mathrm{s}) 2$ to $\sim 20-30$ $(\mathrm{cm} / \mathrm{s}) 2$. Long-lived anticyclones and cyclones display mean coherent displacements, both to the southwest. Westward eddy propagation speeds, close to that of long Rossby waves, increase southward and are consistent with a superposition of beta effect and advection by mean currents. Southward eddy displacements are coherent with the observed mean currents. In the north, anticyclones are seen to consist of Central and Subpolar Mode Water eddies, most of them likely originating from the eastern boundary, whereas in the south, most anticyclonic features result from the influence of "Mediterranean Water Eddies" (meddies) on the upper layers. Cyclonic activity is concentrated in "cyclonic zones," which are seen to exchange floats and water properties.
\end{abstract}

Keywords: northeastern Atlantic; mesoscale eddies; Lagrangian circulation; acoustic floats; drifting buoys; altimetry 


\section{Introduction}

The midlatitude northeast Atlantic intergyre region $\left[36^{\circ}-47^{\circ} \mathrm{N}, 13^{\circ}-23^{\circ} \mathrm{W}\right.$ ) (Figure 1, later the « study area ») is dynamically slack, away from major current systems. In the upper layers, at the level of the North Atlantic Central Water (NACW, from the surface to $\sim 500 \mathrm{~m}$ deep), it is bounded, to the north and northwest, by extensions of the North Atlantic Current (NAC) system near $51^{\circ}-52^{\circ} \mathrm{N}$ [Dietrich et al., 1980, Käse and Krauss, 1996], and to the south and southwest, by the Azores Current (AzC) near $34^{\circ}-35^{\circ} \mathrm{N}$ [Käse and Krauss, 1996, Siedler and Onken, 1996]. It is a known area of formation and subduction of Subpolar Mode Water (SPMW) [McCartney and Talley, 1982]. The POMME (for « Programme Océan Multidisciplinaire MésoÉchelle ») programme [Reverdin et al., submitted] was designed to investigate these processes. Assessing the impact of mesoscale processes on biological phenomena, implied in carbon sequestration and export of primary production, was one of the main objectives of the programme. It was thus deemed essential to describe accurately the mean and mesoscale circulations during the POMME programme. In this dynamically slack region, Lagrangian instruments are well suited to provide long-lasting measurements of the mesoscale field. This paper is concerned with a detailed description of the resulting mean and mesoscale circulations, notably the eddies and their displacement characteristics, during the POMME year (September 2000 - September 2001).

Although the midlatitude northeast Atlantic is a well studied region, there are still uncertainties about the mean and mesoscale circulations. A first picture of the circulation was derived by Helland-Hansen and Nansen [1926] in their classical paper. East of $20^{\circ} \mathrm{W}$, they pointed to a "double-gyre" picture of the weak subsurface circulation, with an anticyclonic gyre north of $40^{\circ}$ $\mathrm{N}$, and a cyclonic one to the south. In their view, the two gyres originate from branches of the NAC, and they depicted a return westward flow just north of $40^{\circ}$ N. Pollard and Pu [1985] and Pollard et al. [1996] found a similar picture for the NACW circulation. Saunders [1982] derived, from hydrographic measurements, a slow southward drift $(<0.5 \mathrm{~cm} / \mathrm{s}$, surface intensified) of the $0-500 \mathrm{~m}$ 
layer, integrated over $10^{\circ}-30^{\circ} \mathrm{W}$ around $41^{\circ} \mathrm{N}$. Using an inverse model, Paillet and Mercier [1997] found, at the upper levels (50 m and $500 \mathrm{~m}$ ), a southward recirculation branch of NAC waters along $22^{\circ} \mathrm{W}$, and a weak eastward branch near $41^{\circ} \mathrm{N}$, which turns southward near the eastern boundary to give the Portugal Current (Dietrich et al., 1980). Their solution also exhibits a weak westward current at the latitude of Cape Finisterre $\left(\sim 43^{\circ} \mathrm{N}\right)$, east of $20^{\circ} \mathrm{W}$ and a weak westward subsurface $(500 \mathrm{~m})$ current north of the $\mathrm{AzC}\left(\sim 37-38^{\circ} \mathrm{N}\right)$, west of $20^{\circ} \mathrm{W}$, which they identified as the «Azores Countercurrent» described by Onken [1993]. Brügge [1995], and more recently Reverdin et al. [2003], used surface drifters to describe a slow mean southward drift in the study area.

Hydrographic data and their inverse modelling, and surface float data, do not seem to present a clear and consistent picture of the various circulation schemes in the study area: Is the NACW circulation southward (as in the works of Saunders [1982], Paillet and Mercier [1997], or in surface float data (e.g. Brügge [1995], Reverdin et al. [2003])) or gyre-like (as in the works of HellandHansen and Nansen [1926] and Pollard et al. [1996]), or a more complex combination of both schemes?

As for the mesoscale circulation, Richardson [1983], Brügge [1995] and more recently Reverdin et al. [2003] with surface drifters, Heywood et al. [1994] using altimetry data, and Stammer and Böning [1996] in their review, depicted a low level of Eddy Kinetic Energy (EKE) in the surface layers, in the $50-100(\mathrm{~cm} / \mathrm{s})^{2}$ range in the study area. Coherent eddy structures were detected in the mesoscale field and their characteristics were investigated during the first intensive dedicated study of the structure of the mesoscale eddies in the region [Le Groupe Tourbillon, 1983]. These authors described a persistent anticyclonic eddy, of radius $50-70 \mathrm{~km}$, near $47^{\circ} \mathrm{N}, 15^{\circ} \mathrm{W}$, slightly to the northeast of the study area. Maximum hydrographic anomalies were found around 500 $\mathrm{m}$ depth, and maximum azimuthal velocities $(\sim 30 \mathrm{~cm} / \mathrm{s})$ at $\sim 20 \mathrm{~km}$ from the center of the eddy, decreasing upward and downward. A hydrographic influence of the eddy was detected down to $4000 \mathrm{~m}$ deep. This eddy was seen to be moving westward at speeds $\sim 2 \mathrm{~cm} / \mathrm{s}$ over several months. A cyclonic eddy was also observed during the 8 month study period. Pingree and Le Cann [1992] 
discovered long-lived anticyclonic eddies in the Bay of Biscay region $\left(43^{\circ}-46^{\circ} \mathrm{N}, 03^{\circ}-10^{\circ} \mathrm{W}\right)$. These eddies were shown to originate from instabilities of the near-surface poleward slope current in the area, and were hence named «Swoddies » (for «Slope Water Oceanic eDDIES»). Two of these eddies were seen to be moving westward over a $\sim 10$ month period, at speeds $\sim 1-2 \mathrm{~cm} / \mathrm{s}$. Paillet [1999] used a set of hydrographic sections to examine the characteristics of NACW eddies in the intergyre region. Diameters and energetics were consistent with former individual studies, and the estimated number of coexisting NACW eddies between $20^{\circ} \mathrm{N}$ and $55^{\circ} \mathrm{N}$, east of $34^{\circ} \mathrm{W}$ was in the range 100-145. The distribution of these eddies was consistent with generation by NAC and AzC instabilities and the slight bias toward anticyclones and decrease of vortex diameters near the eastern boundary pointed to a Swoddy type generation. Martins et al. [2002] studied some characteristics of individual eddies detected from surface drifter observations. Their results suggested southwestward displacements for anticyclonic eddies, at speeds $\sim 1 \mathrm{~cm} / \mathrm{s}$, and were less conclusive for cyclonic eddies. Leach et al. [2002] pointed to a marginally significant northeastward eddy potential vorticity flux in the study area, which would imply a southwestward residual eddy induced transport velocity of $\sim 0.7 \mathrm{~cm} / \mathrm{s}$.

Deeper in the water column, at the Mediterranean Water (MW) level, Richardson et al. [1991] described large (0.4-0.9 psu) salinity anomalies north of $38^{\circ} \mathrm{N}$, which they attributed to Meddies (MEDditerranean Water edDIES) [Armi and Zenk, 1984]. This hypothesis was recently confirmed by Paillet et al. [2002] who thoroughly studied a «Northern Meddy », northwest of the Cape Finisterre area $\left(\sim 45^{\circ} \mathrm{N}, 12^{\circ} \mathrm{W}\right)$, which subsequently drifted southwestward, toward the study area. Several studies [Stammer et al., 1991, Pingree and Le Cann, 1993, Paillet et al., 2002] have shown that Meddies can induce sizeable azimuthal velocities $(\sim 5-10 \mathrm{~cm} / \mathrm{s})$ up to the surface.

The nature, forcing and propagation characteristics of the eddies in the upper layers of the area thus appear rather complex. Are they generated by NAC and AzC instabilities [Paillet, 1999], slope current instabilities [Pingree and Le Cann, 1992], or forced by the wind [White and Heywood, 1995]? How long do they survive as identifiable eddies? What are their propagation characteristics? 
What is the effect of Meddies in the upper layers?

A first near real-time analysis of the circulation in the «POMME area » $\left[38^{\circ}-45^{\circ} \mathrm{N}, 21^{\circ} 20^{\prime}-\right.$ $15^{\circ} 20^{\prime} \mathrm{W}$ ] was conducted by Assenbaum and Reverdin [in press]. In this paper, the authors describe a methodology implemented to estimate the mean and mesoscale horizontal velocity fields. Using objective mapping of all the dynamical observations available in real-time, including some of the Lagrangian data, they depict a near-surface circulation mostly dominated by mesoscale eddies, with an EKE decreasing from the NW $\left(\sim 150(\mathrm{~cm} / \mathrm{s})^{2}\right)$ to the SE $\left(\sim 25(\mathrm{~cm} / \mathrm{s})^{2}\right)$ of the POMME area, with a mean value $\sim 50(\mathrm{~cm} / \mathrm{s})^{2}$. EKE features seasonal variations of order $\sim 20(\mathrm{~cm} / \mathrm{s})^{2}$ during the POMME year (September 2000 - September 2001), linked to variations in the position of the eddies in the NW corner of the area, and to the strength of the frontal area near $41^{\circ} \mathrm{N}$.

In this paper, we present a high resolution quantitative description of the mean and mesoscale circulation in the «study area $»\left(36^{\circ} \mathrm{N}-47^{\circ} \mathrm{N} ; 13^{\circ} \mathrm{W}-23^{\circ} \mathrm{W}\right)$ from September 2000 to September 2001 (later the «POMME year »), and highlight some new results. The Lagrangian instruments, the Lagrangian and altimetry datasets, and the methods used in this study are first documented (Section 2). The mean flow and elementary statistics, like EKE, time and length scales, diffusivity coefficients are then described (Section 3). Using a combined analysis of altimetry and Lagrangian data, we then focus on the description of the displacements and properties of identified individual eddies (Section 4). In Section 5, we discuss these results, notably the high resolution structure of the mean currents and the characteristics of the observed eddies, i.e. their nature, kinematical properties and propagation. We finally conclude with a summary and open questions on the intricate interplay of subduction, mean circulation and the mesoscale eddy field in the area.

2. Data and Methods:

2.1 Lagrangian methods description: 
In order to investigate and map the mean and mesoscale eddy fields during the POMME experiment, several Lagrangian instruments were deployed in the POMME area. They were of seven types: SVP (Surface Velocity Programme) WOCE (World Ocean Circulation Programme) type surface Argos drifting buoys with drogues centered at 15m depth [Sybrandy and Niiler, 1991], Marisonde buoys fitted with 100-200 m long thermistor chains [Blouch et al., 1993], Surdrift buoys with drogues at $400 \mathrm{~m}$ depth [Vrignaud, 2001], monocycle Rafos and VCM (Vertical Current Meter) subsurface acoustic floats [Rossby et al., 1986], multicycle Marvor subsurface acoustic floats [Ollitrault et al., 1994] and Provor profilers [Loaëc et al., 1998].

\subsection{1) Lagrangian instruments:}

\subsection{1.a) Acoustic floats:}

The acoustic Rafos floats [Rossby et al., 1986], were of mono- and multi-cycle types:

2.1.1.a.1) The monocycle floats were "quasi-isobaric", in the sense that they tend to settle to a specific pressure level. These floats were of several types (10 Seascan Rafos floats (nominal pressure 400 dbars), 4 Martec Sivor Rafos Floats (2 at 400 dbars, 2 at 1000 dbars), and 31 VCM floats (25 at nominal pressure level 200 dbars, 6 at 400 dbars). These floats precisely date, every 8 hours (Seascan and Sivor floats) or 4 hours (VCM floats), the Time-Of-Arrival of the signals sent by the acoustic network (see below), and record temperature and pressure. A full description of the technical details, overall performance and problems encountered with the Seascan and Sivor floats may be found in Roudaut [2002a,b].

2.1.1.a.2) The multicycle floats were of Marvor type [Ollitrault et al. ,1994]. The Martec Marvor float is a multi-cycle Rafos type float. It dives to the prescribed nominal pressure (400 dbars for all POMME Marvors) by activating an external bladder. The nominal underwater cycle duration 
was set to 62 days, with a surface stage of less than 1 day. Floats were programmed to listen to the acoustic network every 8 hours. As for the Rafos floats, they record pressure and temperature. A few Marvor floats from the ARCANE [Le Cann et al., 1999] and EUROFLOAT [Speer et al., 1999] experiments, deployed in 1996 and 1997, were still operating in the area, with slightly different programming parameters (nominal pressures 450, 1000, $1500 \mathrm{dbars}$ and $1750 \mathrm{dbars}$, listening once a day). POMME Marvor floats are described by Roudaut [2002c].

For the study area $\left[36^{\circ}-47^{\circ} \mathrm{N}, 13^{\circ}-23^{\circ} \mathrm{W}\right]$ and during the POMME year (Sept $2000-$ Sept 2001), 10.1 float-years were obtained for Seascan and Sivor Rafos floats, 24.4 float-years for Marvor floats (including the ARCANE and EUROFLOAT data), and 15.7 float-years for VCM floats.

\subsection{1.a.3) Acoustic network:}

During the experiment, two networks of acoustic sources were maintained. One source array was transmitting every 8 hours at $260 \mathrm{~Hz}$ to track the Seascan/Sivor/Marvor floats and is described by Roudaut [2002a,b,c]. Over the POMME area, 4-5 sources were typically available to compute float trajectories. A second acoustic array of 4 sources was transmitting at $780 \mathrm{~Hz}$ every 4 hours to track the VCM floats.

An approximate value of positioning error, estimated by combining the last underwater acoustic position and the first Argos fix of Marvor floats at the surface, gave $\sim 3-5 \mathrm{~km}$ for the absolute navigation error and $\sim 1-3 \mathrm{~km}$ for the relative error.

\subsection{1.b) Drogued surface drifters:}

Several types of surface drifters have been used in the context of the POMME experiment.

2.1.1.b.1) SVP type drifters: 
SVP drifters consist of a $25-40 \mathrm{~cm}$ diameter spherical surface float, linked to a $6-7 \mathrm{~m}$ long drogue centered at 15m depth [Sybrandy and Niiler, 1991, Niiler et al., 1995]. They are positioned through the Argos system whose location precision varies between 150 and 1000 meters. Some SVP drifters were equipped with a submergence sensor that allows to detect drogue loss. Only trajectories with drogue attached were used in that case. When drifters were deployed without drogue sensor, trajectories were examined to detect the time of drogue loss. A conservative approach was taken in that process. During the POMME experiment, 24 SVP buoys were deployed, and the POMME area was also sampled by SVP drifters from other programmes. Overall, 44 SVP buoys sampled our study area. A total of 14.5 SVP drifter-years was obtained, for the study area during the POMME year.

\subsection{1.b.2) Marisonde type buoys:}

22 Marisonde GT buoys [Blouch et al., 1993] were deployed by Météo-France (CNRM (Centre National de Recherches Météorologiques)) during the POMME experiment. The surface buoys have an overall height $4.3 \mathrm{~m}$, maximum diameter $0.8 \mathrm{~m}$ and weight $95 \mathrm{~kg}$, and are positioned through the Argos system. The Marisonde buoys deployed during POMME were fitted with thermistor strings 100 to $200 \mathrm{~m}$ long, of diameter $16 \mathrm{~mm}$. As we will later define a surface layer comprising the first 100 meters, we considered that the drift of these buoys could somehow be considered as representative of this layer, although some surface contaminating effects might bias the buoy displacements. Marisonde trajectories were only considered before buoys eventually lost their thermistor chains. A total of 8.8 Marisonde buoy-years was obtained, for the study area and during the POMME year.

2.1.1.b.3) Surdrift type drifters: 
The Surdrift type drifter [Vrignaud, 2001] is an assembly of a small spherical buoy (diameter $\sim 30 \mathrm{~cm}$ ) equipped with an Argos transmitter and a GPS receiver, linked to a $\sim 12 \mathrm{~m}$ long $\mathrm{x} \sim 1 \mathrm{~m}$ diameter holeysock type drogue by a $2.1 \mathrm{~mm}$ diameter Kevlar tether. Hourly GPS positions (precision $\sim 10-20 \mathrm{~m}$ ) were transmitted through the Argos system. Drogue was set to be at $400 \mathrm{~m}$ depth in no-current conditions.

If we assume that the cable below $100 \mathrm{~m}$ is effectively tagging waters between $100 \mathrm{~m}$ and $400 \mathrm{~m}$, Surdrift buoys are acceptable water followers for the 100 - $550 \mathrm{~m}$ layer, which we will define later as the NACW layer. Surdrifts are not fitted with drogue loss sensors, and care was taken to assess drogue loss events. Overall performance and data return are described by Vrignaud [2001]. A total of 27 Surdrift buoys was deployed and 4.6 buoy-years were obtained, for the study area and during the POMME year.

\subsection{1.c) Profiling floats:}

A total of 23 Provor type profiling floats [Loaëc et al., 1998] was deployed in the POMME area. Two parking depths (400 dbars for 17 floats and 1700-1750 dbars for 6 floats) and various cycle durations $(7,10$ and 14 days $)$ were programmed.

After drifting freely at the prescribed parking depth during most of the cycle duration, the Provor profiler dives down to 2000 dbars and performs an ascending profile while measuring temperature and conductivity (when available). At the surface, the subsurface measurements are transmitted in $\sim 8 \mathrm{~h}$, before the float dives again. The Provor profilers are positioned through the ARGOS system. These position data can be used to estimate the deep displacement at the parking depth, since the duration of the subsurface drift makes up more than $90 \%$ of each cycle. Estimated subsurface positions were then linearly interpolated to get daily positions, and subsequently used to compute mean velocities. Due to the lack of position information during the subsurface drift, Lagrangian properties other than the mean currents cannot be derived from this dataset. 
A total of 12.2 Provor float-years was obtained from this dataset, for the study area during the POMME year.

\subsection{2) Lagrangian deployments:}

Part of the Lagrangian instruments was deployed on a grid, at a 100-150 km step, in order to map the Lagrangian properties over the POMME area, at a mesoscale resolution. Other Lagrangian instruments were intentionally launched in eddies during the deployment cruises. The initial deployment of Marvors in September 2000 was complemented by a second deployment in April 2001. Most Rafos floats were launched in autumn 2000, along the western and southern sides of the POMME box. VCM floats deployments took place in October 2000 and were restricted on a grid in the northern $\left(42^{\circ}-45^{\circ} \mathrm{N}\right)$ part of the POMME area, where deep mixed layers and ensuing subduction were expected. Surdrift buoys were deployed in the POMME area, in four batches (April 2000, September 2000, February-March 2001 and April 2001). Most Marisonde buoys were deployed in February 2001 over the POMME area. SVP type buoys were deployed, mostly in the northern part of the POMME area, along $18^{\circ} \mathrm{W}$ or $20^{\circ} \mathrm{W}$. Provor profilers were deployed in the POMME area, from October 1999 to October 2001.

\subsection{3) Lagrangian dataset:}

The time-depth distribution of the resulting dataset for the POMME year (September 2000 September 2001) is presented in Figure 2. The bulk of the dataset is concentrated over the $0-500 \mathrm{~m}$ NACW layer, with a few additional trajectories in the MW layer $(800-1100 \mathrm{~m})$ and the Labrador Sea Water layer (1700-1800 m). In the following descriptions, on the basis of this distribution, two layers are defined: The 0 - 100 m layer comprises SVP drifters, and Marisonde buoys. The $100-550$ m layer comprises Marvor, Rafos, VCM and Provor floats, and Surdrifts drogued at $400 \mathrm{~m} .550 \mathrm{~m}$ 
roughly corresponds to the base of the NACW in the area. The peaks of data distributions are in the 0 - $50 \mathrm{~m}$ and 350 - $400 \mathrm{~m}$ layers. Instrument density in layer 0 - $100 \mathrm{~m}$ sharply increased in February 2001, when Marisondes were deployed, and density in layer 100 - $550 \mathrm{~m}$ was fairly constant from October 2000 to September 2001, when most Rafos and VCM floats surfaced.

As the time sampling rate varied between the different Lagrangian instruments, all data series were resampled at a 1 day timestep. Lagrangian trajectories were then splined to compute daily velocities, with the «Spline toolbox » from Matlab ${ }^{\circledR}$. Profiler data were only used to compute mean velocities.

Lagrangian tracks are shown in Figures 3 for the 0 - $100 \mathrm{~m}$ and $100-550 \mathrm{~m}$ layers. In Figure 3a, for the 100 - $550 \mathrm{~m}$ layer, eddying motions with scales ranging from $\sim 20 \mathrm{~km}$ to $\sim 100 \mathrm{~km}$ are ubiquitous, with a tendency to increase northward. Non eddy-resolving Provor floats are seen to strongly alias these eddies. The average position of eddy A1 (to be described later) is noticeable as a cluster of loops near $43.5^{\circ} \mathrm{N}, 17.5^{\circ} \mathrm{W}$. Looping motions observed in the south and east are mostly related to anticyclones moving southwestward. Southern escape routes from the POMME box seem to concentrate in the southwest corner. In the north, escape routes are more difficult to define. In Figure $3 \mathrm{~b}$, for the $0-100 \mathrm{~m}$ layer, eddying motions are again visible, but the trapping of drifters by the eddies is seen to be much less effective than in the layer below.

Data were then binned into $1^{\circ}$ latitude $\times 1^{\circ} 20^{\prime}$ longitude $(\sim 110 \times 110 \mathrm{~km})$ boxes to derive mean velocities in the two layers. Data distribution for the POMME year is plotted in Figure 4. The number of collected data is seen to be quite significant, with maxima, for the box comprising the A1 eddy data, of 669 days in 100 - $550 \mathrm{~m}$ layer and 157 days for the $0-100 \mathrm{~m}$ layer. This data distribution is exhibiting gradients near the edges of the domain, notably in the $100-550 \mathrm{~m}$ layer. In estimating integrated Lagrangian quantities, like mean currents, such gradients may induce arraybiases. Davis [1991] showed that the velocity field bias could be estimated as:

$$
\boldsymbol{u}_{\text {bias }}=-\kappa^{\infty} \cdot \operatorname{grad} \ln C
$$


where $\kappa^{\infty}$ is the eddy diffusivity tensor, and $\mathrm{C}$ is the data density (in days). As an estimate for $\kappa^{\infty}$, we have used a spatially varying mean of the zonal and meridional diffusivity coefficients $\left(\kappa_{\mathrm{H}}\right.$, see below). In the $100-500 \mathrm{~m}$ layer, velocity biases in the POMME area are less than $4 \mathrm{~cm} / \mathrm{s}$, and generally less than $1 \mathrm{~cm} / \mathrm{s}$. The strongest biases occur in the northwestern part of the study area near $46^{\circ} \mathrm{N}$, outside the POMME area. Examination of the tracks shows that this is again mostly due to the trapping of several floats by persistent eddies in the northwest corner, and will not bias the mean current field. Results for the 0 - $100 \mathrm{~m}$ layer are comparable, although more homogeneous: no strong northwestern bias was found.

A standard Objective Analysis (OA) method was then used to compute maps of the mean stream function field for each layer [Freeland and Gould, 1976], from the binned velocity vectors. Only areas where data density was exceeding ten times the average integral Lagrangian timescale (see below) for the layer were mapped. The adopted covariance function was of the form : $\mathrm{f}(\mathrm{r})=[1+$ $\left.\left(r / r_{0}\right)\right] \exp \left(-r / r_{0}\right)$, where $r$ is the separation distance. Given the gridstep of the analysis $(110 \mathrm{~km})$, lengthscale parameter $r_{0}$ was chosen as $r_{0}=100 \mathrm{~km}$, a compromise between data density and resolution.

2.2 Determination of eddy properties from combined float and altimetry data.

Using results from a quasi-geostrophic (QG) model constrained by altimetry, Assenbaum and Reverdin [in press] proved that combined in situ and altimetry data objective analysis could be used to accurately track persistent eddies. In order to determine the positions of eddies in the study area, Sea Level Anomaly (SLA) fields were downloaded from the CLS (Collecte Localisation Satellites) ftp site (ftp://ftp.cls.fr/pub/oceano/enact/msla/merged/). We used multi-satellite (TOPEX/Poseidon and ERS-2) gridded weekly SLA data (on a $1 / 3^{\circ}$ longitude Mercator grid, with equal resolution in latitude and longitude), produced using the objective mapping method described by Ducet et al. 
[2000]. The space correlation scales used for the objective mapping in the study area are in the range $108-120 \mathrm{~km}$. A zonal $\left[12^{\circ}-25^{\circ} \mathrm{W}\right]$ mean was removed and the fields were filtered using a Butterworth filter with a cut-off period of 1.5 month, to enhance the detection of persistent signals. A monthly analysis period was chosen as it roughly corresponds to the repeat period of the ERS-2 satellite, which has a better spatial resolution than TOPEX/Poseidon. One-month long Lagrangian trajectories were superimposed on the monthly filtered SLA anomalies, to detect looping motions. We screened the 13 maps derived for the POMME year (September 2000 - September 2001) for persistent positive or negative anomalies. Only structures that could be unambiguously detected during at least two months were retained. We ended up with 16 anticyclones and 14 cyclones (see Table 1 for nomenclature and description of these eddies). Then the sequence of altimetry and trajectory maps were analysed to derive mean eddy center positions for each month. In doing this, we manually retained the positions derived from altimetry. Float trajectories, when available, were essential to confirm the position and identity of the eddies. Altimetry anomalies devoid of float tracks were only used when reasonable confidence could be gained on the existence and position of an eddy, based on the analysis for other months. It is important to note that in this combined analysis, we implicitly lowpass space and time signals, considering only scales larger than $\sim 50-100 \mathrm{~km}$ and $\sim 1$ month. Given typical eddy center propagation speeds in the range $1-3 \mathrm{~cm} / \mathrm{s}$, these space and time scales are consistent. The discrepancy between the positions estimated by altimetry and by floats was generally less than $\sim 20 \mathrm{~km}$ for anticyclones. It was generally larger for cyclones, up to $30-40 \mathrm{~km}$, and this is interpreted as a structural difference between anticyclones and cyclones (see below). On occasions, several small cyclones were detected by floats, whereas altimetry only sensed a large « cyclonic zone ». Care was also taken to try not to confuse eddies, as these can appear, split, merge or disappear. It should also be noted that in the altimetry products, covariance functions including westward propagation velocities that depend on geographical position were used. This was seen not to affect the results, as was verified when both altimetry and floats were available. 
3. Mean flow and Lagrangian properties:

The resulting dataset assembled for the POMME year (September 2000 - September 2001) in the study area $\left[36^{\circ}-47^{\circ} \mathrm{N}, 13^{\circ}-23^{\circ} \mathrm{W}\right]$ is first examined, in terms of mean flow, Eddy Kinetic Energy fields and Lagrangian time and length scales.

\subsection{Mean flow and error estimates:}

Maps of the quasi-Eulerian mean circulation in the layers $100-550 \mathrm{~m}$ and $0-100 \mathrm{~m}$ were derived from binning the daily Lagrangian velocities in $1^{\circ}$ latitude $\mathrm{x} 1^{\circ} 20^{\prime}$ longitude boxes, and from OA techniques (Figure 5).

Associated error on binned velocity fields are computed according to Student's t-test (see Krauss and Böning [1987]) as:

$$
u_{e r r}=t_{v ; \alpha / 2} \frac{\sqrt{\overline{u^{\prime 2}}}}{\sqrt{N_{m}}}
$$

where $N_{m}=N / 2 T_{L}$ is the number of degrees of freedom, with $T_{L}$, the integral Lagrangian timescale (in days) and $\mathrm{N}$, the number of float-days in the box. $\mathrm{t}_{\mathrm{v} ; \alpha / 2}$ represents the Student's t-test $\left(v=\mathrm{N}_{\mathrm{m}}-1 ; \alpha / 2=.90\right.$ for a $80 \%$ confidence interval). A minimum number of degrees of freedom $\mathrm{N}_{\mathrm{m}} \geq 5$ was used to accept boxes. The integral Lagrangian timescale $T_{L}$ (mean of zonal $T_{L u u}$ and meridional $T_{L v v}$ values) is computed by time integration of the velocity autocorrelation function to the first zero crossing, with 60-day overlapping windows. In the POMME area, such estimates of $\mathrm{T}_{\mathrm{L}}$ (not shown) range from $\sim 3$ to $\sim 6$ days for the $100-550 \mathrm{~m}$ layer and from $\sim 2.5$ to $\sim 4$ days for the $0-100 \mathrm{~m}$ layer, with a general tendency to increase southwestward in both layers. In estimating the error velocities, we have used the mean values of $T_{L}$ for each layer in the POMME area, $T_{L}=4.5$ days for the $100-550 \mathrm{~m}$ layer 
(minimum number of days per box: 45 ), $\mathrm{T}_{\mathrm{L}}=3.5$ days for the $0-100 \mathrm{~m}$ layer (minimum number of days per box: 35$)$. This finally gives estimates of the errors on the velocity vector, which are plotted as error ellipses (Figure 5). Most of the derived mean vectors are seen to be significant, at the $80 \%$ confidence level, in both layers.

\subsection{Description of mean Lagrangian circulation and EKE:}

Overall, in both layers, the mean flow is weak, in the $1-8 \mathrm{~cm} / \mathrm{s}(\mathrm{resp} .1-13 \mathrm{~cm} / \mathrm{s})$ ranges in the $100-550 \mathrm{~m}$ (resp. 0 - $100 \mathrm{~m}$ ) layers. For the POMME area, the box averaged mean (eastward, northward) flow is, at the $95 \%$ confidence level, $(-0.6 \pm 0.5,-0.8 \pm 0.5) \mathrm{cm} / \mathrm{s}$ in the $100-550 \mathrm{~m}$ layer, $(2.7 \pm 1.3,-3.3 \pm 1.2) \mathrm{cm} / \mathrm{s}$ in the $0-100 \mathrm{~m}$ layer. The mean meridional flow is southward in the upper layers of the POMME area, and decreasing with depth. The mean zonal flow is eastward in the 0 100 m layer, but marginally westward in the $100-550 \mathrm{~m}$ layer. At finer scales ( 110 km resolution), coherent circulation patterns emerge (Figure 5). At both levels, two eastward jets feed the region from the west, at $\sim 45.5^{\circ} \mathrm{N}$, and at $\sim 41^{\circ} \mathrm{N}$. In the $0-100 \mathrm{~m}$ layer, these jets veer southward in the POMME area. In the $100-550$ m layer, after veering southward, they retroflect westward, to form two elongated anticyclonic circulation cells opened to the west. In this layer, between these two cells, a cyclonic cell occupies the central part of the POMME area.

Mean transports can be estimated for the upper layers, from the OA fields, by integrating over the two layers. Overall, for the POMME box, from the surface to $\sim 500 \mathrm{~m}, \sim 1.0 \mathrm{~Sv}$ enter from the west, $\sim 3.0 \mathrm{~Sv}$ from the north, $\sim 4.0 \mathrm{~Sv}$ exit to the south, and the overall transport through the eastern boundary is close to zero. The northern eastward flow transports $\sim 5.5 \mathrm{~Sv}$ between $45^{\circ}-46^{\circ} \mathrm{N}$, while $\sim 2.5 \mathrm{~Sv}$ are entering the POMME area from the west, between $40^{\circ}-42^{\circ} \mathrm{N}$.

Monthly mean currents over the POMME area were also examined (not shown). In both layers, maximum eastward currents occurred in winter (February-March) and in summer (JulyAugust) 2001. Meridional currents were maximum southward in summer (July-September) and 
minimum, marginally northward, in February-April in the $100-550 \mathrm{~m}$ layer, in June in the $0-100 \mathrm{~m}$ layer. A second southward maximum, around April in the $0-100 \mathrm{~m}$ layer, is not seen in the deeper layer.

$\operatorname{EKE}\left(=\frac{\overline{u^{\prime 2}+v^{\prime 2}}}{2}\right)$ in the study area is presented in Figure 6, as velocity variance ellipses. Over the POMME area, mean EKE is $68(\mathrm{~cm} / \mathrm{s})^{2}$ in the $100-550 \mathrm{~m}$ layer $\left(\right.$ resp. $116(\mathrm{~cm} / \mathrm{s})^{2}$ in the 0 $100 \mathrm{~m}$ layer). In both layers, EKE is decreasing from northwest in the NAC southern extension (values $\sim 170(\mathrm{~cm} / \mathrm{s})^{2}\left(\right.$ resp. $\left.\left.\sim 190(\mathrm{~cm} / \mathrm{s})^{2}\right)\right)$, to southeast (values $\sim 30(\mathrm{~cm} / \mathrm{s})^{2}\left(\right.$ resp. $\left.\left.\sim 80(\mathrm{~cm} / \mathrm{s})^{2}\right)\right)$. A secondary maximum is noticeable, in both layers, near $41^{\circ} \mathrm{N}, 18^{\circ}-21^{\circ} \mathrm{W}$, coincident with the location of the mean eastward jet. On the northern side of this relative maximum, a southwest-northeast oriented band of minimum EKE may be seen in both layers, roughly following the southeastern flank of the Azores - Biscay Rise (ABR, Figure 1). In the 0 - 100 m layer, EKE tends to increase again around $36^{\circ}-37^{\circ} \mathrm{N}$, as the $\mathrm{AzC}$ is approached. Ellipse orientation distribution is not particularly organised.

Monthly mean EKE in the POMME area (not shown) range from $\sim 40$ to $\sim 90(\mathrm{~cm} / \mathrm{s})^{2}$ in the 100 - $550 \mathrm{~m}$ layer and from $\sim 70$ to $\sim 150(\mathrm{~cm} / \mathrm{s})^{2}$ in the $0-100 \mathrm{~m}$ layer. Maximum EKE were found to occur in June (resp. March) in the 100 - 550 m layer (resp. 0 - 100 m layer), while minimum EKE were in September in both layers.

3.3 Length scales, diffusivities:

Statistical properties are derived under the classical hypothesis of stationary and homogeneous turbulence (see e.g. Colin de Verdière [1983] or Krauss and Böning [1987]). Integral Lagrangian length scales $\mathrm{L}_{\mathrm{L}}$ are evaluated as:

$$
L_{L}=\sqrt{E K E} T_{L}
$$

In the POMME area, $\mathrm{L}_{\mathrm{L}}$ ranges from $\sim 15$ to $\sim 40 \mathrm{~km}$ in the $100-550 \mathrm{~m}$ layer and from $\sim 20$ to 
$\sim 35 \mathrm{~km}$ in the $0-100 \mathrm{~m}$ layer, with, in both layers, a mean value of $\mathrm{L}_{\mathrm{L}}=29 \mathrm{~km}$. The geographical dependence of $\mathrm{L}_{\mathrm{L}}$ is different from that of $\mathrm{T}_{\mathrm{L}}$ : Lagrangian length scales are decreasing from northwest to southeast, showing that the $\sqrt{E K E}$ term is dominating in (3).

Eddy diffusivity coefficient $\kappa_{H}$ was also estimated classically, a relation valid for times much greater than $\mathrm{T}_{\mathrm{L}}$, as:

$$
\kappa_{H}=E K E T_{L}
$$

In the POMME area, estimates of $\kappa_{\mathrm{H}}$ range from $\sim 500$ to $\sim 4000 \mathrm{~m}^{2} / \mathrm{s}$ in the $100-550 \mathrm{~m}$ layer, with a mean value of $2650 \mathrm{~m}^{2} / \mathrm{s}$ and from $\sim 2000$ to $\sim 5000 \mathrm{~m}^{2} / \mathrm{s}$ in the $0-100 \mathrm{~m}$ layer, with a mean value of $3150 \mathrm{~m}^{2} / \mathrm{s}$. In both layers, $\kappa_{\mathrm{H}}$ distributions resemble more or less that of $\mathrm{EKE}$, increasing northwestward. These estimates may be compared with values given by Colas [2003], $\sim 1500 \mathrm{~m}^{2} / \mathrm{s}$ from Lagrangian data at $450 \mathrm{~m}$ depth, for regions east of $16^{\circ} \mathrm{W}$. Reverdin et al. [submitted] also derived eddy diffusivity coefficients from isopycnal hydrographic properties mapping, for the NACW layer of the POMME area, and found a range of $1000-2000 \mathrm{~m}^{2} / \mathrm{s}$, slightly less than our estimates, possibly due to uncertainties and gradient averaging.

\section{Mesoscale eddies:}

Examination of Lagrangian tracks and altimetry maps showed that anticyclonic (resp. cyclonic) flows, defined by positive (resp. negative) SLA extrema, and closed loops in float tracks, on 20-100 km scales could be followed on timescales of several months. These eddies, thus defined as 20-100 km size patches in SLA, persisting for several months, and exhibiting closed float looping motions, are now examined, in order to derive their kinematical properties and lifetimes.

4.1 Results of eddy center tracking: 
Using the combined float and altimetry method (see section 2.2), anticyclones (resp. cyclones) could be tracked on average 7.4 months (resp. 7.3 months). Anticyclones A1, A2, and A7 and cyclones C5 and C6 were followed during one year. Individual eddy center tracks derived from this analysis are presented in Figure 7. The center tracks relative to the initial center position of individual eddies are plotted in Figure 8. Although far from regular, the eddy center translations are seen to be organised. Overall, eddies are moving in a general west-southwestward direction. Mean (eastward, northward) eddy center velocities computed over all available monthly velocities, are $(-0.9,-0.4) \mathrm{cm} / \mathrm{s}$ for anticyclones, $(-0.9,-0.3) \mathrm{cm} / \mathrm{s}$ for cyclones, with a standard deviation $\sim 1.0 \mathrm{~cm} / \mathrm{s}$ in all cases. Maximum monthly speeds are $4.4 \mathrm{~cm} / \mathrm{s}$ for anticyclones, $3.6 \mathrm{~cm} / \mathrm{s}$ for cyclones, both in a west-southwestward direction. Kolmogorov-Smirnov type statistical tests showed that there is no significant difference, at the $95 \%$ confidence level, between anticyclone and cyclone center velocity distributions. No seasonal time-dependence in eddy center velocities was found. There is some indication of the existence of two groups in anticyclone translations, with some eddies moving roughly westward (A1, A3, A4, A6, A31), and others (A2, A5, A7, A6, A10, A32), travelling more southwestward. Some eddy translations are seemingly affected by deep topography. This is noticeable for the anticyclonic A1 eddy, whose westward translation is halted when encountering the ABR [Gascard et al., in preparation]. These «stalling periods» may also be observed for anticyclone A7, and cyclones C4 and C6, at least for part of their trajectories. With no marked deep topography, eddy translations seem more regular (e.g. A2, A6, C7). The computed distribution of eddy center velocities was binned into $2^{\circ}$ latitude x $3^{\circ}$ longitude boxes (Figure 9). The overall westsouthwestward trend is readily visible, with a tendency for eddy center speeds to increase from north to south, with no significative difference between anticyclones and cyclones. As measured by altimetry, the mean SLA of both anticyclones and cyclones (not shown) exhibit a tendency to increase northwestward, in a manner similar to the distribution of EKE.

4.2 Lagrangian description of eddies: 


\subsubsection{General description:}

To investigate more closely eddy type motions, Lagrangian trajectories were visually inspected, to detect loops and cusps, indicative of eddying motions. We have used the same criterion as Shoosmith et al. [submitted], i.e. an eddy was defined by two or more consecutive loops in the same direction. Velocity and temperature time series were also examined to get estimates of start and end of looping motions. As defined above, few eddying motions were detected in the $0-100 \mathrm{~m}$ layer, and Figure 10 displays the resulting dataset in the 100 - $550 \mathrm{~m}$ layer. In the study area, for this 100 $550 \mathrm{~m}$ layer, more anticyclonic (30 different float tracks, for a total duration of 2829 days) than cyclonic (24 different float tracks, for a total duration of 1458 days) looping motions were observed in this dataset, although this distribution might be biased, as some floats were intentionally deployed in eddies, notably anticyclonic ones, and as some eddies were sampled by more than one float. A summary of individual eddies characteristics is given in Table 1. Looping durations, computed using subsurface floats only, were significantly longer for anticyclones than for cyclones, at the $95 \%$ confidence level. For anticyclones, the mean looping duration was 117 days and the maximum (313 days) was obtained for float mv007 in anticyclone A33. For cyclones, the mean looping duration was 65 days and the maximum (185 days) was obtained for float seascan112 in an unnamed cyclone in the southwestern corner of the POMME area (see Figure 10 and Table 1). These figures compare well with Shoosmith et al. [submitted], who did a similar study for the North Atlantic, north of $40^{\circ}$ N. From the Lagrangian dataset (see Figure 10), anticyclones are seen to be distributed throughout the study area, whereas cyclonic loopers tend to be more numerous north of $41^{\circ} \mathrm{N}$. Looping float tracks were binned to derive estimates of geographical distribution. Anticyclonic loopers show a bipolar distribution, with maxima around $43^{\circ}-45^{\circ} \mathrm{N}$ and $40^{\circ}-41^{\circ} \mathrm{N}$, while cyclonic loopers are concentrated between anticyclones, near $41^{\circ}-43^{\circ} \mathrm{N}$. As seen by floats, translation of eddies is fairly chaotic, with anticyclones moving mostly in a general southwestward direction, like in the combined 
altimetry-Lagrangian analysis. This behavior is more marked in the south of the POMME area, with some long southwestward moving looping trajectories. Northern anticyclones moved more southward (northwestern eddies A5, A7) or did not not move significantly, like the A1 eddy near $\left(43.5^{\circ} \mathrm{N}, 17.5^{\circ} \mathrm{W}\right)$, right above the $\mathrm{ABR}$ [Gascard et al., in preparation]. From the Lagrangian dataset, there is no consistent picture of cyclone translation.

Filtered SLA near the estimated eddy center, with zonal $\left(13^{\circ}-23^{\circ} \mathrm{W}\right)$ mean removed, is given in Table 1, but it does not reflect the true instantaneous values, and is given as a relative estimate of eddy amplitude. Kinematical properties are also examined: Center motion and azimuthal velocities were determined using the method outlined by Paillet et al. [2002]. Radial azimuthal velocity distributions are plotted in Figure 11. Maximum azimuthal velocity averaged over one looping period $V_{\theta \max }$, and the corresponding average distance from the eddy center $r_{\max }$ were combined to estimate a Rossby number $\mathrm{Ro}=2 \mathrm{~V}_{\theta \max } / \mathrm{fr}_{\max }$ (Table 1). Although the POMME hydrographic surveys were intended to map the POMME area at a $\sim 55 \mathrm{~km}$ resolution, some CTD stations were found within eddies, and are used to characterise hydrographic properties of eddies. T,S anomalies are estimated with respect to a zonal mean in the POMME area.

\subsubsection{Anticyclones:}

From Figure 11, it is obvious that there are noticeable kinematical differences among anticyclones. Accordingly, anticyclones were grouped into three categories: «Northwestern Anticyclones » (NW-AC, located in the northwestern quadrant $\left.\sim\left[42^{\circ}-46^{\circ} \mathrm{N}, 23^{\circ}-18^{\circ} \mathrm{W}\right]\right)$, « Northeastern Anticyclones » (NE-AC, located in the northeastern quadrant $\sim\left[42^{\circ}-46^{\circ} \mathrm{N}, 18^{\circ}-13^{\circ}\right.$ W]) and «Southern Anticyclones» (S-AC, located south of $\left.\sim 42^{\circ} \mathrm{N}\right)$. NW-ACs (A5-A7) have significant $(\sim 25 \mathrm{~cm} / \mathrm{s})$ maximum observed float azimuthal velocities at $\sim 400 \mathrm{~m}$ depths and $\sim 30-40$ $\mathrm{km}$ radiuses, and weaker $(\sim 10 \mathrm{~cm} / \mathrm{s})$ at depth ( $\sim \mathrm{MW}$ level). NE-ACs (A1-A13) exhibit a much tighter « core », with maximum observed float azimuthal velocities observed at the base of NACW, 25 
$\mathrm{cm} / \mathrm{s}$ again, at a radiuses $\sim 15-20 \mathrm{~km}$, decreasing with depth. This results in Rossby numbers in a $\sim 2: 1$ ratio between NE-ACs $(\sim 0.34)$ and NW-ACs $(\sim 0.13-0.17)$. At the NACW level, S-ACs (A2, A3, A10) display weaker $(\sim 15 \mathrm{~cm} / \mathrm{s})$ azimuthal velocities at radiuses $\sim 30-50 \mathrm{~km}$, resulting in even weaker Rossby numbers, $\sim 0.08-0.13$. Furthermore, when available, float data indicate that S-ACs azimuthal velocities tend to increase with depth (A2), pointing to Meddy-type anticyclones, with anticyclonic motions extending into the NACW layer. This was confirmed from available hydrographic data for A2, A6 and A10. Observed trapping radiuses are $\sim 40-50 \mathrm{~km}$ for NW-ACs and S-ACs, while they are around $20 \mathrm{~km}$ for NE-ACs. These different characteristics altogether suggest that these eddies correspond to three different types of anticyclones.

The characterictics of a representative of each of the three anticyclone types are now described.

A1, representative of NE-AC eddies (Table 1 and Figure 11) was the most thoroughly sampled eddy during POMME, tracked by floats from October 2000 to September 2001. This eddy was located in the $43^{\circ}-44^{\circ} \mathrm{N}$ latitude band, and entered the POMME area from the east in October 2000. Its westward motion was halted when it encountered the ABR in January 2001. A1 then slowly moved anticyclonically around the deep topography. A1 was apparently a Swoddy type eddy [Pingree and Le Cann, 1992], with maximum azimuthal velocities around $25 \mathrm{~cm} / \mathrm{s}$ at radiuses $\sim 15$ $20 \mathrm{~km}$ and at $\sim 500-600 \mathrm{~m}$ depths (Figure 12b and Table 1), resulting in Rossby numbers up to 0.34 . Its core was thus quite compact, but it was also observed that $\mathrm{A} 1$ exhibited significant $(\sim 18 \mathrm{~cm} / \mathrm{s})$ azimuthal velocities at radiuses $\sim 50-60 \mathrm{~km}$, with a resulting overall diameter $\sim 150 \mathrm{~km}$. Its hydrographic anomalies encompassed a $\sim 800 \mathrm{~m}$ thick layer, with negative temperature and salinity anomalies from the surface to $\sim 500 \mathrm{~m}$ deep, and positive anomalies below, down to $\sim 800 \mathrm{~m}$ deep. A deep $\mathrm{O}_{2}$ core maximum (dissolved oxygen $>5.7 \mathrm{ml} / \mathrm{l}$, anomaly from surrounding waters $>1.5 \mathrm{ml} / \mathrm{l}$ ) was found at $\sim 600 \mathrm{~m}$ depths. This was the largest dissolved oxygen value observed at these depths during the whole POMME experiment. Hydrographic anomalies, positive in temperature $\left(\sim 1.2{ }^{\circ} \mathrm{C}\right)$ and salinity ( $\sim 0.2 \mathrm{psu}$ ), were also found at the MW level, around $1200 \mathrm{~m}$ depth, indicating that A1 
either interacted previously with a Meddy, or was entraining MW in its course. The A1 origin and properties will be fully described and analysed by Gascard et al. [in preparation].

A2, representative of S-AC eddies, was tracked from September 2000 to August 2001. It exhibited the longest tracked displacement, over $600 \mathrm{~km}$. During these 12 months, A2 displayed a consistent southwestward translation, at a mean velocity $(-1.8,-1.3) \mathrm{cm} / \mathrm{s}$. Maximum observed azimuthal velocities are in the range $13-17 \mathrm{~cm} / \mathrm{s}$ at $24-45 \mathrm{~km}$ from center and at $\sim 400 \mathrm{~m}$ depths. Maximum Rossby number $(\sim 0.13$ at $24 \mathrm{~km})$ is in fact obtained at the MW level. Examination of available nearby CTDs confirmed that A2 was indeed a Meddy (maximum positive temperature and salinity anomalies of $\sim 2.5{ }^{\circ} \mathrm{C}$ and $\sim 0.4$ psu at $\sim 1200 \mathrm{~m}$ depth). A2 is possibly of the «northern Meddy » type described by Paillet et al. [2002], with a strong surface expression. This suggests a possible interaction with a NACW eddy, and hydrographic evolutions between POMME cruises point to such an event in autumn-winter, that could have resulted in the birth of a new eddy, A4, in December 2000.

A7, a NW-AC representative, is, by several counts, the biggest eddy observed during POMME. It was tracked during the whole POMME year, from September 2000 to September 2001. During that period, it moved slowly (mean speed $<1 \mathrm{~cm} / \mathrm{s}$ ) to the southwest. This weak mean speed in fact results from a prolonged 7 month stall, when encountering King's Trough deep seamounts (Figure 1). At the NACW level, maximum azimuthal velocities $\sim 25 \mathrm{~cm} / \mathrm{s}$ were observed at radiuses 30 to $50 \mathrm{~km}$ (Table 1 and Figure 11), and loop diameters could reach $140 \mathrm{~km}$. A deep float at $\sim 850 \mathrm{~m}$ level clearly indicated the decay of azimuthal velocities with depth. A maximum Rossby number of $\sim 0.17$ was obtained at radius $\sim 26 \mathrm{~km}$ and $\sim 350 \mathrm{~m}$ depth. Hydrography also shows that A7 was different from NE-ACs and S-ACs: it was cold and fresh at depths greater than $\sim 800 \mathrm{~m}$ (maximum temperature anomaly $\sim-2{ }^{\circ} \mathrm{C}$ and salinity anomaly $\sim-0.5 \mathrm{psu}$ at $\sim 1200 \mathrm{~m}$ depth). Density anomalies were negative from $\sim 200 \mathrm{~m}$ depth down to the MW level, and positive above, indicative of a near surface intensified eddy. The deepest mixed layer observed during the POMME experiment was found in this eddy, in March 2001. A7 was possibly generated as the result of the splitting of a bigger 
A7+A8 eddy, and A8 was observed to disappear in March 2001. Overall, A7 is reminiscent of the anticyclonic eddy observed near $47^{\circ} \mathrm{N}, 15^{\circ} \mathrm{W}$, by Le Groupe Tourbillon [1983].

\subsubsection{Cyclones:}

We give here a quick summary of representative properties of cyclones.

As an example of the observed cyclones, C4 (Figure 12a) was located in the western part of the POMME area. During its tracking period, from September 2000 to July 2001, when it disappeared, C4 was located on the eastern flank of the ABR. Its overall displacement in 11 months was of $100 \mathrm{~km}$ to the south. Some of the floats that sampled C4 (e.g. seascan114, Figure 12a) displayed cyclonic loops, quickly moving cyclonically at the periphery of $\mathrm{C} 4$. We believe that this could explain the discrepancy between floats and altimetry in eddy center determination, which was larger for cyclones than for anticyclones. Maximum azimuthal velocities in these loops were $\sim 14$ $\mathrm{cm} / \mathrm{s}$, at $\sim 400 \mathrm{~m}$ depth and at a radius of $22 \mathrm{~km}$, resulting in an estimated Rossby number of $\sim 0.14$. C4 exhibited maximum cold and fresh anomalies in the $1000-1500 \mathrm{~m}$ depth range (maximum temperature anomaly $\sim-2{ }^{\circ} \mathrm{C}$ and salinity anomaly $\sim-0.3$ psu at $\sim 1200 \mathrm{~m}$ depth).

Different cyclonic areas were seen to exchange floats. A particularly striking example is shown in Figure 12b: Float mv011 originates from cyclone C5, while mv016 originates from cyclone C4. All these floats end up in C2, sampled by floats vcm066 and mv015. It may thus be more appropriate to speak of «cyclonic zones» rather than of true cyclones. This behavior was never observed for anticyclones in our dataset.

As may be seen in Figure 11, we could not detect obvious differences between azimuthal velocity distributions as a function of radius for cyclones. Even for deep cyclones, the azimuthal velocity distribution fits well with the overall distribution. Maximum trapping radiuses are of order $30 \mathrm{~km}$, significantly lower than for NW-ACs and S-ACs, and maximum azimuthal velocities are around $15-20 \mathrm{~cm} / \mathrm{s}$. 


\section{Discussion}

The POMME Lagrangian dataset, combined with altimetry data, allows for a detailed analysis of mean currents and eddy properties and propagation in the region of the Northeast Atlantic Ocean situated between the North Atlantic Current and the Azores Current. We will now discuss and analyse these results, and how they relate to previous work.

\subsection{Mean currents}

Mean currents observed during the POMME year may be synthesised by zonal and meridional averaging (Figure 13). In Figure 13a, alternating bands of eastward and weaker westward currents, of 2-6 cm/s amplitude and $1-2^{\circ}$ in latitude in width, clearly appear. These mean currents are sheared on the vertical, with maximum eastward currents near the surface $(0-100 \mathrm{~m}$ layer $)$, at latitudes $40^{\circ}-41^{\circ} \mathrm{N}$ (as in the work by Paillet and Mercier [1997]) and $45^{\circ}-46^{\circ} \mathrm{N}$ (see Brügge [1995]), and maximum westward currents in the $100-550 \mathrm{~m}$ layer, at latitudes $38^{\circ}-40^{\circ} \mathrm{N}$ and $43^{\circ}-$ $44^{\circ} \mathrm{N}$ (again as in the work by Paillet and Mercier [1997]). Minimum shear is obtained in the south and north of the POMME area, where currents in both layers are similar. Eastward currents are associated with relative maxima in EKE (see notably near $41^{\circ} \mathrm{N}$ ). Zonally averaged mean meridional currents are clearly southward in the $0-100 \mathrm{~m}$ layer, marginally so in the $100-550 \mathrm{~m}$ layer. Their southward component also shows a tendency to increase to the south. These meridional currents may be affected by «array bias » effects, notably near the northern and southern POMME box limits. Meridionally averaged currents (Figure 14) nevertheless confirm the overall southward component of the meridional currents, with maximum southward currents around $20^{\circ} \mathrm{W}$, in both layers, to be related to the southward branch found by Paillet and Mercier [1997] near $22^{\circ} \mathrm{W}$.

Bower et al. [2002] showed that the eastward currents across the Mid-Atlantic Ridge (MAR), 
at the $\sigma_{\theta}=27.5$ level ( $\sim 900 \mathrm{~m}$ deep in the mid-latitude northeast Atlantic), flow preferentially over fracture zones, north of $48^{\circ} \mathrm{N}$. Further south, this preferential crossing is much less clear, but these authors find (their Figure 3a) an eastward current at latitudes $45^{\circ}-46^{\circ} \mathrm{N}$, east of the MAR, from $\sim 20^{\circ}$ $\mathrm{W}$ to $\sim 23^{\circ} \mathrm{W}$, similar to the one we observe at shallower depths in the same area (Figures 5 and 13) (see also Brügge [1995]). Although there is no marked fracture zone in the MAR at that latitude, we note that this location corresponds to a transition in MAR depths, from deep in the north to shallower in the south. Results from Bower et al. [2002] also suggest that this flow at $45^{\circ}-46^{\circ} \mathrm{N}$ may be part of the flow crossing the MAR at Maxwell Fracture Zone (Figure 1), around $48^{\circ} \mathrm{N}$.

At $41^{\circ} \mathrm{N}$, the location of the southern eastward flow (Figure 13), we also note that there exists a fracture zone in the MAR, at $\sim 40.5^{\circ} \mathrm{N}, 30^{\circ}-27^{\circ} \mathrm{W}$, the Kurtchatov Fracture Zone (see Figure 1), although no direct flow connexion is proven from our dataset. At that latitude, Bower et al. [2002] also find an eastward branch, from $\sim 22^{\circ} \mathrm{W}$ to $\sim 15^{\circ} \mathrm{W}$, which is the southern limb of a cyclonic cell, reminiscent of the one we observe in the $100-550 \mathrm{~m}$ layer.

Beside this possible connection with fracture zones in the MAR, another classical dynamical explanation of zonal currents is provided by Rhines [1975] as the result of the competing effects of QG turbulence and Rossby Waves (RW). The inverse energy cascade which governs the large scale dynamics of QG turbulence is interrupted by RW dispersion. In this process, alternate zonal currents are generated. The scale of interruption, the so-called Rhines scale, $L_{R}(=\sqrt{U / \beta})$, where $U$ is a typical mesoscale velocity scale (which we take as $\sqrt{E K E} \sim 10 \mathrm{~cm} / \mathrm{s}$ for the POMME area), and $\beta$ $\sim 1.610^{-11} \mathrm{~m}^{-1} \mathrm{~s}^{-1}$, is around $80 \mathrm{~km}$ in the POMME area. The meridional separation of the two zonal eastward currents in the study area is observed to be $\sim 500 \mathrm{~km}\left(\sim 41^{\circ} \mathrm{N}\right.$ to $\left.\sim 46.5^{\circ} \mathrm{N}\right)$, which is indeed very close to $2 \pi \mathrm{L}_{\mathrm{R}}$. Furthermore, the latitudes of the NAC and $\mathrm{AzC}$ at $\sim 20^{\circ} \mathrm{W}$ are respectively $\sim 52^{\circ} \mathrm{N}$ and $\sim 35^{\circ} \mathrm{N}$ (e.g. Brügge [1995]), and the meridional spacing between this system of eastward currents $\left(\mathrm{AzC}, \sim 41^{\circ} \mathrm{N}, \sim 46.5^{\circ} \mathrm{N}, \mathrm{NAC}\right)$ is in the range $500-700 \mathrm{~km}$, roughly consistent with Rhines scales estimations. 
Moreover, the mean currents are not zonal, but exhibit a significant meridional component. A southwestward flow was also noted by Bower et al. [2002], at the $\sim 1000 \mathrm{~m}$ level and at the Labrador Sea Water level $(\sim 1750 \mathrm{~m})$, over the ABR. A visual inspection of Figure 5 indeed seems to suggest a relation with deep topography. In the POMME area, there is an overall peak of distribution of the mean currents in the southwestward direction, roughly aligned with topography, notably the ABR. Secondary peaks in distribution are eastward and westward. When we tested correlation of f/h contours with mean currents at the $\sim 110$ x $110 \mathrm{~km}$ resolution of mean currents, this relation does not seem to hold, although there is perhaps a weak tendency for currents to be aligned along topography, with topography on their left.

Overall, in the 100 - 550 m layer of the study area, the resulting pattern of the mean currents is a tripolar structure, with two elongated anticyclonic cells around $44^{\circ} \mathrm{N}$ and $40^{\circ} \mathrm{N}$, separated by a cyclonic cell around $42^{\circ} \mathrm{N}$. These cells are opened to the west, and closed at the eastern boundary $\left(\sim 14^{\circ} \mathrm{W}\right)$. The northern anticyclone - cyclone dipole is also noticeable at the MW level in the work of Bower et al. [2002]. We note the close correspondence between the anticyclonic and cyclonic cells in the mean currents in the $100-550 \mathrm{~m}$ layer (Figure 5a) and the preferred locations of the anticyclonic eddies (Figures 7 and 10). Assenbaum and Reverdin [in press] already noticed that some of the features in the mean velocity field were remaining imprints of long-lived eddies.

The westward / southwestward branches of the flow in the $26.8<\sigma_{\theta}<27.2$ density classes, roughly corresponding to the SPMW and to the 100 - $550 \mathrm{~m}$ layer, transport mode water to greater depths (e.g. Pollard et al. [1996]) and thus contribute to subduction. Figure 5a shows that there are two main different branches in the POMME area:

- a « northern branch », near $42^{\circ}-44^{\circ} \mathrm{N}$,

- and a « southern branch », south of $40^{\circ} \mathrm{N}$, mostly exiting the POMME area in the southwest corner. There are hints of a third branch, in the southeast corner of the POMME area.

5.2 Eddy propagation and properties 
Eddy propagation in the ocean is a long-standing problem: Accurate long term observations are difficult to collect and may be affected by a host of external influences, and complete theory should include multiple dynamical effects, like differential rotation ( $\beta$ effect), stratification, nonlinearity and bottom topography.

Observations of NACW eddy displacements in the area are limited (e.g. Le Groupe Tourbillon [1983], Martins et al. [2002]). At the MW level, Meddy displacements were studied using a large Lagrangian dataset by Richardson et al. [2000] in the Iberian and Canary Basins, south of $40^{\circ}$ $\mathrm{N}$. They found that Meddies tend to move southwestward at typical speeds $\sim 2 \mathrm{~cm} / \mathrm{s}$, and can survive up to $\sim 5$ years. From Lagrangian studies, Shoosmith et al. [submitted] found that eddies are generally following the mean current in the northern North Atlantic.

Altimetry data have been intensively used to study long RW propagation (e.g. Challenor et al. [2001], Osychny and Cornillon [2004]). Reliable eddy tracks are more difficult to obtain from altimetry data, owing to the small scales of individual eddies, relative to the altimetry sampling scales. Morrow et al. [2004] recently used altimetry data to study the propagation pathways of anticyclonic and cyclonic eddies in three oceanic eastern regions. They found that the eddies generally propagate westward, and that anticyclones (resp. cyclones) exhibit an equatorward (resp. poleward) translation.

From a theoretical point of view, following the pioneering work of Nof [1981], CushmanRoisin et al. [1990] derived generalisations of eddy motions with a single-layer model on a flat bottom $\beta$ plane. They concluded that quasi-geostrophic vortices propagate at a constant speed, which is that of long nondispersive RW, $-\beta \mathrm{R}_{\mathrm{d}}^{2}$, and that there is no difference between cyclonic and anticyclonic QG eddies. The first order correction to westward velocities, due to non-linearity, is to increase the speed of anticyclones, and decrease that of cyclones. Non-linearities affect meridional eddy motions, with anticyclones moving preferentially southwestward, and cyclones northwestward (in the northern hemisphere). These displacements have been analysed as the effects of an induced 
dipolar circulation, called «beta-gyre » (see e.g. Sutyrin and Flierl [1994]).

In Figure 15, zonally averaged eddy center velocities in the POMME area are plotted as a function of latitude. Westward zonal velocities are increasing to the south, from $\sim-0.5 \mathrm{~cm} / \mathrm{s}$ to $\sim-1.5$ $\mathrm{cm} / \mathrm{s}$ and are seen to be very close to the phase speed of long Rossby Waves, $\beta \mathrm{R}_{\mathrm{d}}{ }^{2}$, estimated from Chelton et al. [1998]. It can also be observed that there is no significant difference between anticyclones and cyclones, which is the prediction of Cushman-Roisin et al. [1990] for QG eddies. Furthermore, differences between zonal eddy velocities and long RW phase speed reflect quite well the mean zonal currents in the upper layers (Figure 13). Zonal velocities tend to be higher than that of long RW in the south, where the observed mean zonal current is westward over both layers, and lower in the $41^{\circ}-42^{\circ} \mathrm{N}$ and $45^{\circ}-46^{\circ} \mathrm{N}$ latitude bands, where the mean currents are eastward. The ratio between these differences and the upper layer currents is $\sim 0.1-0.3$, reflecting that these deep reaching eddies are also feeling the advection effect of the slower currents at depth. Zonally averaged meridional eddy centers velocities (Figure $15 \mathrm{~b}$ ) are southward, of order $-0.5 \mathrm{~cm} / \mathrm{s}$, increasing to the south. They are again very similar for anticyclones and cyclones, and are seen to somehow reflect the mean meridional currents (Figure 13). Removing the periods when eddies stalled over topographies (e.g. like A1 from January to September 2001) did not significantly change the results.

Morrow et al. [2004] also find that in the low EKE northeast Pacific, the poleward propagation of cyclones is less clear than in their two other cases, the southeast regions of the Atlantic and the Indian oceans, where the EKE is larger. They did not present eddy tracks in the northeast Atlantic, so no direct comparison with our results is possible. On the other hand, Challenor et al. [2001], in their study of non-zonal RW propagations with 3D Radon transforms, found westsouthwestward RW propagation in the POMME area.

What could explain these rather unusual findings, that both anticyclones and cyclones propagate southwestward? Possible explanations may lie in the eddy generation processes. It has been shown that the slope currents of the midlatitude northeast Atlantic generate long-lived (of order one year or more) anticyclonic eddies, as baroclinic dipoles moving away from the boundary, like 
the Meddies at the MW level [Pingree and Le Cann, 1993, Bower et al., 1997, Paillet et al., 2002, Serra et al., 2002] and the Swoddies at the NACW level [Pingree and Le Cann, 1992]. The cyclonic component of the dipole then tends to weaken while separating from the anticyclone (Meddy or Swoddy). The resulting anticyclone subsequently drifts into the ocean for long times (one year or more [Richardson et al., 2000, Pingree and Le Cann, 1992]), whereas cyclonic cores tend to be short-lived, with lifetimes of order of months or even less. At the eastern boundary of the POMME box $\left(\sim 15^{\circ} \mathrm{W}\right)$, we thus expect a WSW flux of anticyclonic coherent eddies, Meddies and Swoddies, from the eastern boundary. These anticyclones are likely to organise and bias the mesoscale field structure, in which many other processes are involved, like RW propagation from the eastern boundary [Challenor et al., 2001, Osychny and Cornillon, 2004], wind forcing [White and Heywood, 1995], local generation by baroclinically unstable currents, and interaction with mean currents.

Another point may be worth noting: The individual displacements of the surface-intensified eddies seemed to be affected by topography. Stalling periods were observed in the vicinity of deep topographies for northern anticyclones (A1, A7) and cyclones (C4, C8), indicating that these eddies have deep expressions, at least down to $\sim 3000 \mathrm{~m}$ depths, and likely more. This was confirmed by relatively scarce deep hydrographic measurements [L. Prieur, pers. comm., 2005]. This deep expression was already noticed for The Tourbillon Group anticyclone [Le Groupe Tourbillon, 1983], further northeast, and for Meddies [Paillet et al., 2002], further east. Deep topography, roughly aligned NE-SW in the study area (see Figure 1), is thus likely to constrain the southwestward propagation of these deep-reaching eddies.

Central Water anticyclones in the POMME area have been seen to fall into three categories: the « Northwestern anticyclones » (NW-ACs), the «Northeastern anticyclones » (NE-ACs) and the « Southern anticyclones » (S-ACs). The distribution of these anticyclones is believed to reflect their generation, with NE-ACs being likely of Swoddy type [Pingree and Le Cann, 1992] generated by slope current instabilities in the West Iberia - Bay of Biscay area. The NW-ACs might also be generated in a similar fashion further north, by slope instabilities in the Goban Spur - West Ireland 
area. They could also result from baroclinic instabilities of the $45^{\circ}-46^{\circ} \mathrm{N}$ eastward flow. Observed SACs are believed to be the surface manifestations of Meddies. These may be either genuine (meaning that they may be generated during the formation of the Meddy), or may result from coalescence with NACW anticyclones, notably NE-ACs. All these differences have important consequences on transport and mixing properties of the anticyclones. Trapping radiuses are significantly larger for NW-ACs and S-ACs on one hand $(\sim 40 \mathrm{~km})$ than for NE-ACs on the other hand $(\sim 20 \mathrm{~km})$. Differences between trapping radiuses of NE-ACs and NW-ACs, and thus of their typical sizes, may again reflect their generation processes. Assuming a uniform $\sim 500 \mathrm{~m}$ thickness, we can roughly compute the trapped transport associated with NACW anticyclones at the western boundary of the POMME box, to $\sim 0.25 \mathrm{~Sv}$, as we estimate that $2 \mathrm{NW}$-ACs and $1 \mathrm{~S}$-AC crossed this boundary during the POMME year. Taking into account that we may have missed an equal number of eddies would merely double this figure. The same computation for the southern limit of the POMME box, where 2 S-ACs were observed to cross the boundary, gives a trapped eddy transport of $\sim 0.15 \mathrm{~Sv}$. We estimate that 2 NE-ACs (A1, A32) and 3 S-ACs (A6, A10, A32) entered the POMME box through its eastern boundary, for an approximate total transport $\sim 0.30 \mathrm{~Sv}$. No NE-AC was observed to make its way out of the POMME area through the western or southern boundaries.

The differences observed between the combined altimetry-Lagrangian analysis and the floats only analysis are thought to be linked to the effective scales seen by the two analyses. This is confirmed by observations for anticyclone A1 [Gascard et al., in preparation], showing a compact core $\sim 30-40 \mathrm{~km}$ in diameter, embedded in a much larger structure, up to $150 \mathrm{~km}$ in diameter. Altimetry is accurately seing the large $(\sim 100 \mathrm{~km})$ eddy structure, but not the details of the inner core, which might wobble inside the larger structure, and these core motions are captured by the floats.

Although the combined altimetry-Lagrangian analysis gave similar characteristics for anticyclones and cyclones, regarding sizes, lifetimes and propagation, the Lagrangian properties of cyclones are seen to differ from anticyclones. First, Lagrangian trapping radiuses are smaller $(\sim 20-30$ $\mathrm{km}$ ), comparable to that of NE-ACs. Furthermore, cyclones may be more accurately described as 
« cyclonic zones » (i.e. what is seen in the combined altimetry-Lagrangian analysis), sometimes encompassing several cyclonic cores (i.e. the ones trapping individual floats). These cores tend to be located at the periphery of, and orbiting cyclonically around, the cyclonic zones. They might result from baroclinic instabilities in these zones, and their lifetimes is significantly smaller, by a factor of two, than that of the anticyclonic cores seen by the floats. These cyclonic zones are seen to exchange floats trapped in cores, a process not seen for anticyclones. This assymetry, if systematic, will have profound implications for mixing and dispersion in the area. True transport in cyclones is also likely to be significantly smaller than for anticyclones.

To illustrate the implication of these results on subduction, we refer to the work of Paillet [1999]. North of $45^{\circ} \mathrm{N}$, this author found that significantly more anticyclones than cyclones ( 2 out of 3 eddies) contain mode water. Few mode water containing eddies, and only cyclones, were found south of the subduction line $\left(40^{\circ}-42^{\circ} \mathrm{N}\right)$. Arguing that cyclones would tend to move northwestward in a fluid at rest, Paillet [1999] concluded that «advective dynamics seem appropriate to describe the ventilation regime in the area $»$. Our observations that anticyclones may contain newly ventilated water [Gascard et al., in preparation], and that both anticyclones and cyclones are moving southwestward are important in subduction fluxes. On modelling grounds, Valdivieso et al. [accepted], indeed found a large effect of the mesoscale eddy field on ventilation rates in the area. In the density class range of interest here $\left(26.8<\sigma_{\theta}<27.1\right)$, they showed that the eddies, in their $1 / 6^{\circ}$ resolution primitive equation model, tend to counteract the subduction/entrainment by the mean flow, much reducing the total subduction rate. These issues concerning the delicate interplay between mean circulation, eddies and subduction processes, will be later examined with the full POMME dataset.

6. Summary and conclusions

This study has examined the characteristics of the mean and mesoscale circulation of the 
upper layers $(\sim 0-500 \mathrm{~m})$ of the intergyre region of the Northeastern Atlantic, from Lagrangian and altimetry data collected during the POMME programme in 2000-2001. The mean circulation was seen to consist of two weak surface intensified eastward flows approximately 100-200 km wide, at $40^{\circ}-41^{\circ} \mathrm{N}$ and $45^{\circ}-46^{\circ} \mathrm{N}$. A weak southward mean component, increasing to the south, exists on top of these zonal currents. The flows were seen to retroflect westward at depth, forming a system of two anticyclonic cells, separated by a cyclonic cell, both opened to the west. This results in a mean southwestward current in the 100 - 500m layer, that is possibly linked to deep topography, roughly aligned in the same direction. For the POMME box $\left[38^{\circ}-45^{\circ} \mathrm{N}, 21^{\circ} 20^{\prime}-15^{\circ} 20^{\prime} \mathrm{W}\right]$, mean transport in the upper layers is $\sim 3.0 \mathrm{~Sv}$ from the northern boundary, $\sim 1.0 \mathrm{~Sv}$ from the west. This transport exits through the southern boundary, the transport through the eastern boundary being close to zero.

EKE is decreasing from the NW to the SW of the study area, from $\sim 100-200(\mathrm{~cm} / \mathrm{s})^{2}$ to $\sim 20$ $30(\mathrm{~cm} / \mathrm{s})^{2}$, with relative maxima in the vicinity of the two mean eastward flows. Lagrangian timescales are of order 3.5 days for the 0 - $100 \mathrm{~m}$ layer, and 4.5 days for the $100-550 \mathrm{~m}$ layer, and Lagrangian length scales are of order $30 \mathrm{~km}$ for both layers. Estimates of diffusivity coefficients are $\sim 2500-3000 \mathrm{~m}^{2} / \mathrm{s}$ for both layers.

From a combined altimetry-Lagrangian analysis, NACW anticyclones and cyclones are observed to be long-lived (up to one year and likely more) and exhibit very similar properties in lifetimes, sizes and propagation. These surface-intensified eddies are seen to be roughly $100-150 \mathrm{~km}$ in diameter, and their propagation, for both anticyclones and cyclones, is in a west-southwestward direction, at typical speeds $\sim 1-2 \mathrm{~cm} / \mathrm{s}$. The westward propagation can be accounted for by a combination of advection by mean currents and of $\beta$ effect, at long Rossby Waves phase speed. Meridional propagation is consistent with advection by mean currents. An additional possibility is that the NE-SW oriented deep topography is somehow constraining the overall southwestward eddy propagation. Deep topography is also observed to affect eddy propagation, notably as stalling periods.

Differences between NACW anticyclones and cyclones arise when floats are considered. 
Float trapping by anticyclones is significantly longer than for cyclones, by a factor of two, with mean trapping durations respectively $\sim 4$ months and $\sim 2$ months. Then there are differences among anticyclones, that are linked to their geographical location, and origins. Northwestern anticyclones are larger than northeastern anticyclones, and we propose that they are both generated in a Swoddy type fashion [Pingree and Le Cann, 1992], and that southern anticyclones are the surface manifestation of Meddies generated on the slopes of Western Iberia [Bower et al., 1997, Paillet et al., 2002]. Cyclones are better described as «cyclonic zones », where several cyclonic cores could occasionally be observed, and sometimes exchanged between different zones.

Eddy trapped transport at the NACW level was estimated to lie in the range $0.3-0.5 \mathrm{~Sv}$, in a west-southwestward direction, mostly in the anticyclones.

The dataset points to multiple and complex interactions between eddies populating the area, mean currents and deep topography. Other unresolved issues are the fate of these eddies and their role in subducting NACW waters. Further work is needed to fully appraise this Lagrangian dataset, notably by combining it with hydrographic and eulerian measurements. POMME was designed as a multi-disciplinary programme, with a strong biogeochemical component. Our analysis may be thought of a first step to give a physical framework for these studies, and clearly further work is needed to fully integrate other observations. 


\section{Acknowledgements}

N. Cortes carefully prepared, L. Gourmelen deployed, and T. Reynaud, A. Faisant, L. Gourmelen and G. Roudaut processed the LPO (Laboratoire de Physique des Océans) and CMO (Centre Militaire d'Océanographie) floats. M. Rafizadeh processed the VCM floats. J. Paillet coordinated the field work. The acoustic network was maintained as a cooperation between SHOM (Service Hydrographique et Océanographique de la Marine), LPO and LODYC (Laboratoire d'Océanographie Dynamique et Climat). B. Le Cann, G. Reverdin and J.C. Gascard are supported by CNRS (Centre National de la Recherche Scientifique). The POMME experiment was funded by the INSU (Institut National des Sciences de l'Univers) / PATOM (Programme ATmosphère et Océan Multi-Échelles) and PROOF (PROcessus biogéochimiques dans l'Océan et Flux) programmes. The Marisonde and SVP buoys are operated and processed by CMM (Centre de Météorologie Marine, MétéoFrance). The altimeter products were produced by the CLS Space Oceanographic Division as part of the Environment and Climate EU ENACT project (EVK2-CT2001-00117) and with support from CNES (Centre National d'Études Spatiales). We also thank the associate editor (A. Oschlies) and the two anonymous referees for their helpful comments. 


\section{Reference list}

Armi, L., and W. Zenk, Large lenses of highly saline Mediterranean Water (1984), J. Phys. Oceanogr., 14, 1560-1576.

Assenbaum, M., and G. Reverdin, Near Real-Time Analyses of the mesoscale Circulation during the POMME Experiment, Deep-Sea Res. I, in press.

Blouch, P., R. Le Guen, J. Rolland, M. Tremant, J. Y. Hervouet, F. X. Fusey and J. Quenet (1993), Expérience SEMAPHORE, bouées «Marisonde», Note de travail $\mathrm{n}^{\circ} 12 \mathrm{du}$ Centre de Météorologie Marine, CNRM, 129 pp..

Bower, A. S., L. Armi, and I. Ambar (1997), Lagrangian Observations of Meddy Formation during A Mediterranean Undercurrent Seeding Experiment, J. Phys. Oceanogr., 27, 2545-2575.

Bower, A., B. Le Cann, T. Rossby, W. Zenk, J. Gould, K. Speer, P. L. Richardson, M. D. Prater, and H. M. Zhang (2002), Directly-measured mid-depth circulation in the northeastern North Atlantic Ocean, Nature, 419, 603-607.

Brügge, B. (1995), Near-surface mean circulation and kinetic energy in the central North Atlantic from drifter data, J. Geophys. Res., 100, 20543-20554.

Challenor, P. G., P. Cipollini, and D. Cromwell (2001), Use of 3D Radon transform to examine the properties of oceanic Rossby waves, J. Atmos. and Oceanic Technol., 18, 1558-1566.

Chelton, D. B., R. A. deSzoeke, M. G. Schlax, K. El Naggar, and N. Siwertz (1998), Geographical variability of the first-baroclinic Rossby radius of deformation,J. Phys. Oceanogr., 28, 433-460.

Colas, F. (2003), Circulation et dispersion lagrangiennes en Atlantique Nord-Est, PhD Thesis, Université de Bretagne Occidentale, Brest, France, n 943, 259 pp..

Colin de Verdière, A. (1983), Lagrangian eddy statistics from surface drifters in the eastern North Atlantic, J. Mar. Res., 41, 375-398.

Cushman-Roisin, B., E. P. Chassignet, and B. Tang (1990), Westward motion of mesoscale eddies, J. Phys. Oceanogr., 20, 758-768. 
Davis, R. (1991), Observing the general circulation with floats, Deep-Sea Res., 38, suppl. 1, 531-571.

Dietrich, G., K. Kalle, W. Krauss, and G. Siedler (1980), General Oceanography (English translation), Wiley, Chichester, UK.

Ducet, N., P. Y. Le Traon, and G. Reverdin (2000), Global high resolution mapping of ocean circulation from TOPEX/Poseidon and ERS-1/2,J. Geophys. Res., 105, 19477-19498.

Freeland, H. J., and W. J. Gould (1976), Objective analysis of meso-scale ocean circulation features, Deep-Sea Res., 23, 915-923.

Helland-Hansen B., and F. Nansen (1926), The eastern North-Atlantic, Geophysiske Publicajoner, 4, 2, 1-76.

Heywood, K. J., E. L. McDonagh and M. A. White (1994), Eddy kinetic energy of the North Atlantic subpolar gyre from satellite altimetry, J. Geophys. Res., 99, 22525-22539.

Käse, R. H., and W. Krauss, The Gulf Stream, the North Atlantic Current (1996), and the Origin of the Azores Current, in «The Warmwatersphere of the North Atlantic Ocean», W. Krauss ed., Gebrüder Borntraeger, 291-337.

Krauss, W., and C. W. Böning (1987), Lagrangian properties of eddy fields in the northern north Atlantic as deduced from satellites-tracked buoys, J. Mar. Res., 45, 259-251.

Leach, H., S. J. Bowerman, and M.E. McCulloch (2002), Upper-Ocean Eddy transports of Heat, Potential Vorticity, and Volume in the Northeastern North Atlantic - «Vivaldi $1991 », J$. Phys. Oceanogr., 32, 2926-2937.

Le Cann, B. , K. G. Speer, A. Serpette, J. Paillet and T. Reynaud (1999), Lagrangian observations in the intergyre North-East Atlantic during the ARCANE and EUROFLOAT projects: Early results. WOCE Int. Newsl., 34, 25-27.

Le Groupe Tourbillon (1983), The Tourbillon experiment: a study of a mesoscale eddy in the eastern North Atlantic, Deep-Sea Res., 30, 5A,475-511. 
Loaëc, G., N. Cortès, M. Menzel and J. Moliéra (1998), PROVOR: a hydrographic profiler based on MARVOR technology, IEEE-Oceans'98.

McCartney, M. S., and L. D. Talley (1982), The Subpolar Mode Water of the North Atlantic Ocean, J. Phys. Oceanogr. , 12,1169-1188.

Martins, C. S., M. Hamann, and A. F. G. Fiúza (2002), Surface circulation in the eastern North Atlantic, from drifters and altimetry, J. Geophys. Res.,107(C12), 3217, doi:10.1029/2000JC000345.

Morrow, R., F. Birol, D. Griffin and J. Sudre (2004), Divergent pathways of cyclonic and anti-cyclonic ocean eddies, Geophys. Res. Lett., 31, L24331, doi:10.1029/2004GL020974.

Niiler, P. P., A. S. Sybrandy, K. Bi, P. M. Poulain, and D. Bitterman (1995), Measurements of the water-following capability of holey-sock and TRISTAR drifters, Deep-Sea Res. I, 42,11/12, 1951-1964.

Nof, D. (1981), On the $\beta$-induced movement of isolated baroclinic eddies, J. Phys. Oceanogr., 11, 1662-1672.

Ollitrault, M., G. Loaëc, and C. Dumortier (1994), Marvor: a multicycle Rafos float. Sea Technology, 35, 2: 39-44.

Onken, R. (1993), The Azores Countercurrent, J. Phys. Oceanogr., 23, 1638-1646.

Osychny, V., and P. Cornillon (2004), Properties of Rossby Waves in the North Atlantic Estimated from Satellite Data, J. Phys. Oceanogr., 34, 61-76.

Paillet, J. (1999), Central Water vortices of the Eastern North Atlantic, J. Phys. Oceanogr., 29, 2487-2503.

Paillet, J., B. Le Cann, X. Carton, Y. Morel, and A. Serpette (2002), Dynamics and evolution of a Northern Meddy, J. Phys. Oceanogr., 32, 55-79.

Paillet, J., and H. Mercier (1997), An inverse model of the eastern North Atlantic general circulation and thermocline ventilation, Deep-Sea Res. I, 44, 8, 1293-1328.

Pingree, R.D., and B. Le Cann (1992), Three anticyclonic Slope Water Oceanic eDDIES 
(SWODDIES) in the southern Bay of Biscay in 1990, Deep-Sea Res. I, 39, 1147-1175.

Pingree, R.D., and B. Le Cann (1993), A shallow Meddy (A Smeddy) from the secondary Mediterranean salinity maximum ,J. Geophys. Res., 98, 20169-20185.

Pollard R.T., M.J. Griffiths, S.A. Cunningham, J.F. Read, F.F. Perez, and A.F. Rios (1996), Vivaldi 1991 - A study of the formation, circulation and ventilation of Eastern North Atlantic Central Water, Prog. Oceanogr., 37, 167-192.

Pollard, R.T., and S. Pu (1985), Structure and Circulation of the upper Atlantic Ocean northeast of the Azores, Prog. Oceanogr., 14, 443-462.

Reverdin G., P.P. Niiler, and H. Valdimarsson (2003), North Atlantic Ocean surface currents, J. Geophys. Res., 108(C1), 3002, doi:10.1029/2001JC001020.

Rhines, P.B. (1975), Waves and turbulence on a $\beta$-plane, J. Fluid Mech., 69, 417-443.

Richardson, P. L. (1983), Eddy kinetic energy in the North Atlantic from surface drifters, $J$. Geophys. Res., 88, 4355-4367.

Richardson, P. L., M.S. McCartney, and C. Maillard (1991), A search for Meddies in historical data, Dyn. of Atmosph. and Oceans, 15, 241-265.

Richardson, P. L., A.S. Bower, and W. Zenk (2000), A census of Meddies tracked by floats, Prog. Oceanogr., 45, 209-250.

Rossby, T.D., D. Dorson, and J. Fontaine (1986), The RAFOS system, J. Atm. Ocean. Techn., 4, 672-679.

Roudaut, G. (2002a), Traitement et validation des données des flotteurs lagrangiens monocycles Seascan du SHOM, Rapport n²48 EPSHOM/CMO/CM/NP, 39 pp..

Roudaut, G. (2002b), Traitement et validation des données des flotteurs lagrangiens monocycles Sivor du SHOM, Rapport n88 EPSHOM/CMO/CM/NP, 22 pp..

Roudaut, G. (2002c), Les flotteurs Marvor de l'expérience POMME: bilan du fonctionnement et analyse du comportement, Rapport n47 EPSHOM/CMO/CM/NP, 36 pp..

Saunders, P.M. (1982), Circulation in the eastern North Atlantic, J. Mar. Res., 40, suppl, 641- 
657.

Serra, N., S. Sadoux, I. Ambar, and D. Renouard (2002), Observations and Laboratory Modeling of Meddy Generation at Cape St. Vincent, J. Phys. Oceanogr., 32, 3-25.

Siedler, G., and R. Onken, Eastern Recirculation (1996), in «The Warmwatersphere of the North Atlantic Ocean », W. Krauss ed., Gebrüder Borntraeger, 339-364.

Speer, K.G., J. Gould, and J. Lacasce (1999), Year-long float trajectories in the Labrador Sea Water of the eastern North Atlantic Ocean, Deep-Sea Res. II, 46, 165-197.

Stammer, D., and C.W. Böning (1996), Generation and Distribution of Mesoscale Eddies in the North Atlantic Ocean, in «The Warmwatersphere of the North Atlantic Ocean », W. Krauss ed., Gebrüder Borntraeger, 159-193.

Stammer, D., Hinrichsen H.H., and R. H. Käse (1991), Can Meddies be detected by satellite altimetry?, J. Geophys. Res., 96, 7005-7014.

Sutyrin, G. G., and G. R. Flierl (1994), Intense vortex motion on the beta plane: development of the beta gyres, J. of the Atmos. Sci., 51, 773-790.

Sybrandy, A. L., and P. P. Niiler (1991), WOCE/TOGA Lagrangian drifter construction manual, SIO Ref. 91/6, WOCE Rep. 63, 58 pp., Scripps Inst. of Oceanogr., La Jolla, Calif..

Valdivieso da Costa, M., H. Mercier, and A. M. Tréguier, Effects of the mixed-layer time variability on kinematic subduction rate diagnostics, J. Phys. Oceanogr., accepted.

Vrignaud, C. (2001), Traitement et validation des données des flotteurs lagrangiens de type Surdrift de la campagne POMME, Rapport n²130 EPSHOM/CMO/CM, 88 pp..

White, M. A., and K. J. Heywood (1995), Seasonal and interannual changes in the North Atlantic subpolar gyre from Geosat and TOPEX/POSEIDON altimetry, J. Geophys. Res., 100, 24931-24941.

Zhou, M., J.F. Paduan, and P.P. Niiler (2000), Surface currents in the Canary Basin from drifter observations, J. Geophys. Res., 105, 21893-21911. 


\section{Figure captions}

Figure 1: General map of the study area. Major topographic features are labelled. Topography (ETOPO5) is gray-shaded with $500 \mathrm{~m}$ shade intervals and the $4000 \mathrm{~m}$ isobath is plotted as a solid line. The «POMME area » is overlaid as a solid line rectangle, and the «study area » as a dashed line rectangle.

Figure 2: Time (months) - depth (m) distribution of the whole POMME Lagrangian dataset. Several «pressure instabilities » that affected Marvor type floats are visible as individual dots scattered between the lines.

Figure 3: Lagrangian tracks of the POMME drifters and floats from September 2000 to September 2001 in the 100 - $550 \mathrm{~m}$ layer (a) and the 0 - $100 \mathrm{~m}$ layer (b). Crosses indicate the beginning of the tracks (or track segments in the case of Marvor floats). Smoothed topography is represented as gray shades, in $1000 \mathrm{~m}$ depth ranges, and depths contours are indicated. The «POMME area » is overlaid as a solid line rectangle. Mean position of anticyclone A1 is indicated as a white circle.

Figure 4: Lagrangian data distribution (in float-days) in $1^{\circ}$ latitude $\mathrm{x} 1^{\circ} 20^{\prime}$ longitude boxes for the period September 2000 - September 2001. (a) 100 - $550 \mathrm{~m}$ layer, (b) 0 - $100 \mathrm{~m}$ layer. A minimum threshold of 10 times the average Lagrangian timescale for each layer was used (100 - 550 m layer: minimum number of days 45 - maximum day-number $669 ; 0$ - 100 m layer: minimum number of days 35 - maximum number of days 157). Number of days is given in each box and colorcoded according to gray shaded colorbar.

Figure 5: Mean currents derived from Lagrangian data in $1^{\circ}$ latitude x $1^{\circ} 20^{\prime}$ longitude boxes for the period September 2000 - September 2001. (a) 100 - 550 m layer, (b) 0 - 100 m layer. Error ellipses are plotted. A minimum threshold of 10 times the average Lagrangian timescale for each layer is used. A velocity scale is plotted. Smoothed deep topography is represented as in Figure 3. Dashed lines represent streamfunction derived from Objective Analysis (see text): Contour intervals are $1500 \mathrm{~m}^{2} / \mathrm{s} \mathrm{(a)}$ and $3000 \mathrm{~m}^{2} / \mathrm{s} \mathrm{(b)}$. 
Figure 6: Velocity variance ellipses derived from Lagrangian data in $1^{\circ}$ latitude $\mathrm{x} 1^{\circ} 20^{\prime}$ longitude boxes for the period September 2000 - September 2001. EKE is equal to the arithmetic mean of the principal axes. (a) 100 - $550 \mathrm{~m}$ layer, (b) 0 - $100 \mathrm{~m}$ layer. The scale, at the bottom left, represents a variance circle with radius of mentioned value. A minimum threshold of 10 times the average Lagrangian timescale for each layer is used. Topography is represented as in Figure 3.

Figure 7: Monthly trajectories of eddy centers determined from combined Lagrangian -altimetry data. Anticyclone $(« \mathrm{~A} »)(\operatorname{cyclone}(« \mathrm{C} »))$ tracks are in red (blue). Labels identify eddies near their trajectories. Dots indicate mid-month eddy positions during the period September $2000-$ September 2001. 2000-2001 months are labelled along the tracks. Topography is represented as in Figure 3.

Figure 8: Eddy center trajectories relative to their initial detected position during the period September 2000 - September 2001. 2000-2001 mid-month positions (labelled) are plotted for anticyclones (solid line; open circles) and cyclones (dashed line; open triangles). Eddies are labelled at the end of their relative tracks. East and North positions are given in $\mathrm{km}$.

Figure 9: Eddy center velocities binned in $2^{\circ}$ latitude $\times 3^{\circ}$ longitude boxes for the period September 2000 - September 2001. Anticyclone arrows are plotted as solid lines, cyclones arrows are dashed. The number at the base of the arrows (upper: anticyclone; lower: cyclones) indicate the number of monthly vectors used in the estimation (a minimum threshold of 3 months was used). A velocity scale $(1 \mathrm{~cm} / \mathrm{s})$ is plotted. Topography is represented as in Figure 3.

Figure 10: Looping float trajectories in the 100 - $550 \mathrm{~m}$ layer, during the period September 2000 - September 2001. Selected floats made at least two consecutive loops in the same direction. Anticyclonic (cyclonic) tracks are in red (blue). First underwater float position is indicated as an open circle. Gaps in trajectories are due to the surface phase of Marvor floats. Day number (from 01/01/2000) is labelled every 30 days along the tracks. Topography is represented as in Figure 3.

Figure 11: Eddy azimuthal velocities $(\mathrm{cm} / \mathrm{s})$ as a function of distance $(\mathrm{km})$ from eddy center. a) Northwestern (A5, A7 and an unnamed anticyclone), b) northeastern (A1, A13), c) southern (A2, 
A3, A10) anticyclones and d) cyclones (C2, C4, C5, C11, C12) are distinguished (see text). Estimations are for the 100 - $550 \mathrm{~m}$ layer (stars), the 800 - $1100 \mathrm{~m}$ layer (open circles) and the 17001800 m layer (downward triangles).

Figure 12: Selected trajectories for cyclonic eddies. All floats are in the $100-550 \mathrm{~m}$ layer. a) Cyclone $\mathrm{C} 4 ; \mathrm{b})$ «Cyclonic exchange » («CE ») (see text). Float identification is plotted at start of trajectory, marked by a filled dot. Solid, dashed and dashed dot lines are used to distinguish between trajectories. Months are indicated along trajectories, as labelled crosses. Topography is represented as gray shades, in $1000 \mathrm{~m}$ depth ranges, and depths contours are indicated.

Figure 13: Zonally averaged float velocities and EKE as a function of latitude for the period September 2000 - September 2001. All quantities are zonally averaged over longitudes $22^{\circ}-15^{\circ} 20^{\prime} \mathrm{W}$. Solid lines are for the 100 - $550 \mathrm{~m}$ layer, and dash-dotted lines for the $0-100 \mathrm{~m}$ layer. a) east velocities $(\mathrm{cm} / \mathrm{s}), \mathrm{b})$ north velocities $(\mathrm{cm} / \mathrm{s})$ and $\mathrm{c})$ EKE $\left((\mathrm{cm} / \mathrm{s})^{2}\right)$. In each case, we have averaged over the box data of Figures 5 and 6. Standard deviations are plotted as error bars.

Figure 14: Meridionally averaged float velocities and EKE as a function of longitude for the period September 2000 - September 2001. All quantities are meridionally averaged over latitudes $38^{\circ}-46^{\circ} \mathrm{N}$. Solid lines are for the $100-550 \mathrm{~m}$ layer, and dash-dotted lines for the $0-100 \mathrm{~m}$ layer. a) east velocities $(\mathrm{cm} / \mathrm{s}), \mathrm{b})$ north velocities $(\mathrm{cm} / \mathrm{s})$ and $\mathrm{c})$ EKE $\left((\mathrm{cm} / \mathrm{s})^{2}\right)$. In each case, we have averaged over the box data of Figures 5 and 6. Standard deviations are plotted as error bars.

Figure 15: Eddy centers velocities computed from the combined altimetry-Lagrangian analysis (see text), as a function of latitude, for the period September 2000 - September 2001. a) East velocities of anticyclone (solid) and cyclone (dashed) centers $(\mathrm{cm} / \mathrm{s})$. b) North velocities of anticyclone (solid) and cyclone (dashed) centers $(\mathrm{cm} / \mathrm{s})$. Velocities were averaged over $2^{\circ}$ latitude bands. Standard deviations are plotted as dotted lines. In a), the open circles indicate the mean phase speed of long Rossby Waves as computed by Chelton et al. [1998] (http://www.coas.oregonstate.edu/research/po/research/chelton/), in $1^{\circ}$ latitude x $1^{\circ}$ longitude boxes over the longitude band $13^{\circ}-23^{\circ} \mathrm{W}$. 
10. Tables

\begin{tabular}{|c|c|}
\hline \multicolumn{2}{|l|}{ (L) squxuruog } \\
\hline \multicolumn{2}{|l|}{$\nexists 0$} \\
\hline \multirow{2}{*}{$>^{ \pm}$} & (ury) ${ }^{\mathrm{xan}}$ I sn plpey \\
\hline & (s/un)prods \\
\hline \multirow[b]{6}{*}{ 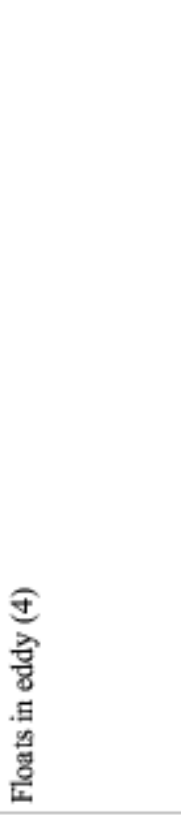 } & (ppuuKК $\delta$ ) әџер puə \\
\hline & 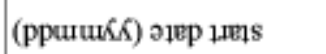 \\
\hline & 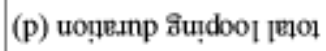 \\
\hline & 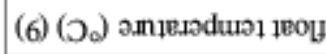 \\
\hline & (8) (u) पldop 1вo[J \\
\hline & 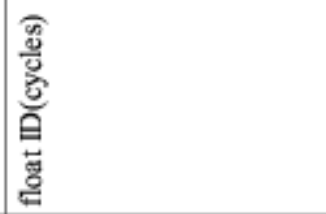 \\
\hline \multirow{2}{*}{ 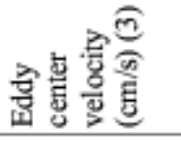 } & $>$ \\
\hline & $D$ \\
\hline (z) VTS Kppg & 总 \\
\hline \multirow{2}{*}{ 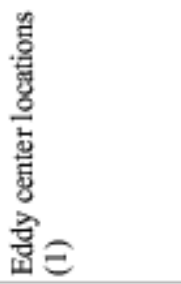 } & 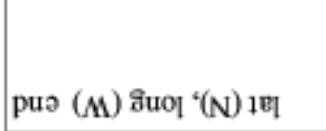 \\
\hline & 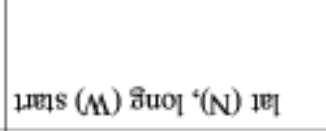 \\
\hline \multirow{3}{*}{ 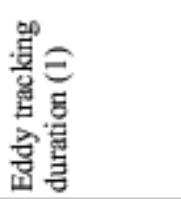 } & (umu $\delta \kappa)$ प1uour pus \\
\hline & 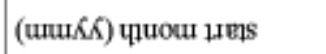 \\
\hline & (squour) ןణ101 \\
\hline \multicolumn{2}{|l|}{ 窎。 } \\
\hline
\end{tabular}

\begin{tabular}{|c|c|c|c|c|c|}
\hline 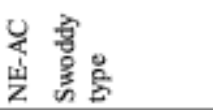 & 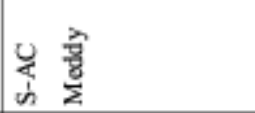 & 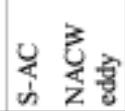 & & 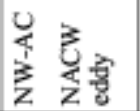 & 丞 \\
\hline స్ & 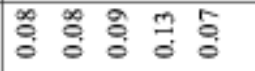 & $\stackrel{\infty}{\circ} \stackrel{\infty}{0}$ & $\stackrel{\circ}{\circ}$ & 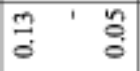 & \\
\hline$\div$ สึ $8 \div 9$ & ษ & 요 & a & $\infty \mathbb{n}^{\prime} 8$ & \\
\hline สิ $\cong \infty$ ส & $\Xi \cong \cong \cong r$ & $0=$ & $气$ & 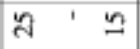 & \\
\hline 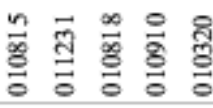 & 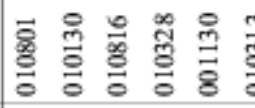 & 를 & 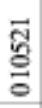 & 웡 웡 & \\
\hline 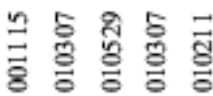 & 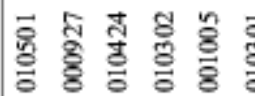 & 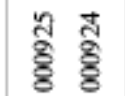 & 동 & 강 웡 & \\
\hline 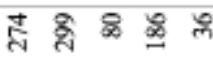 & 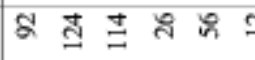 & 의 बิ & 9 & 吉 워 & \\
\hline 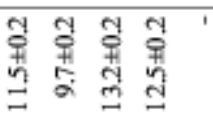 & 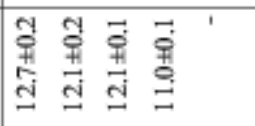 & 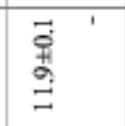 & ' & 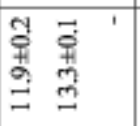 & $I^{\prime}$ \\
\hline 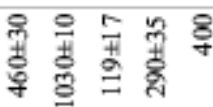 & 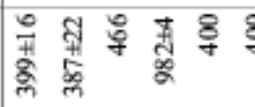 & 字 & 子 & 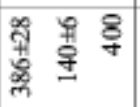 & \\
\hline
\end{tabular}

\begin{tabular}{|c|c|c|c|c|c|}
\hline 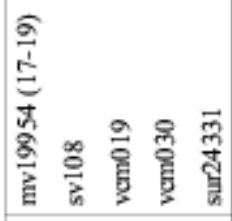 & 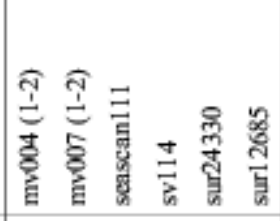 & 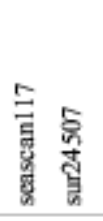 & 等 & 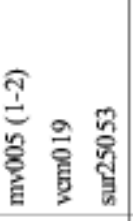 & \\
\hline $\overrightarrow{0}$ & $\frac{3}{1}$ & $\stackrel{+}{\circ}$ & $\stackrel{A}{8}$ & $\stackrel{\infty}{\rightarrow}$ & $\because$ \\
\hline$\hat{\phi}$ & $\stackrel{\infty}{\rightarrow}$ & $\stackrel{\circ}{i}$ & $\hat{\varphi}$ & $\stackrel{m}{7}$ & $\stackrel{\circ}{i}$ \\
\hline I্ & 푱 & $\underset{E}{\mathbb{E}}$ & $\underset{\infty}{\mathbb{7}}$ & $\underset{t}{\mathbb{I}}$ & F \\
\hline $\begin{array}{l}\stackrel{\infty}{0} \\
\overrightarrow{1} \\
\dot{\sigma} \\
\dot{y}\end{array}$ & 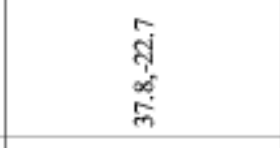 & 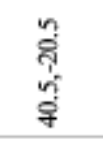 & 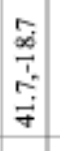 & 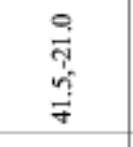 & 告 \\
\hline $\begin{array}{l}n \\
\text { s. } \\
b \\
b \\
\dot{b}\end{array}$ & 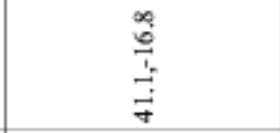 & $\begin{array}{l}\frac{3}{4} \\
\frac{1}{5} \\
\overrightarrow{+}\end{array}$ & 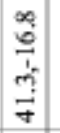 & $\begin{array}{l}\stackrel{a}{\vec{b}} \\
\dot{b} \\
\dot{+}\end{array}$ & $\begin{array}{l}\infty \\
\stackrel{\infty}{1} \\
-1 \\
\infty \\
\infty \\
\infty\end{array}$ \\
\hline$\frac{8}{0}$ & $\stackrel{0}{0}$ & ఏ్ & $\frac{8}{0}$ & $\stackrel{g}{\circ}$ & $\frac{2}{0}$ \\
\hline 8 & हิ & శ్ & $\frac{1}{8}$ & 8 & $\overrightarrow{8}$ \\
\hline 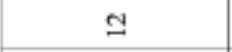 & 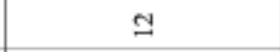 & in & ○ & 0 & 잉 \\
\hline द & \&ै & 2 & 安 & ₹ & $\%$ \\
\hline
\end{tabular}

Table 1a 


\begin{tabular}{|c|c|c|c|c|c|c|c|c|c|}
\hline 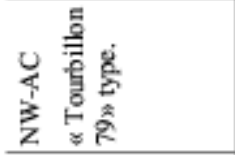 & 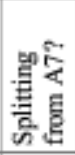 & 窇 & 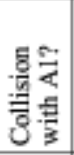 & & $\begin{array}{l}2 \\
0 \\
4 \\
\text { 岁飞 }\end{array}$ & & & & 筦 \\
\hline '吉气 今 & 1 & $\stackrel{m}{0}$ & 1 & ' & के & ' & & & $\stackrel{\frac{\pi}{0}}{0}$ \\
\hline 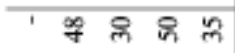 & ' & สి & . & & $a$ & & & & สิ สิ \\
\hline ' 9 莳 & ' & $\cong$ & ' & & 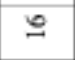 & & & 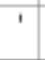 & $\Xi \approx$ \\
\hline 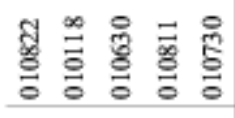 & 1 & ఫิ & $\overrightarrow{8}$ & 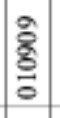 & $\begin{array}{l}\overrightarrow{\mathrm{s}} \\
\stackrel{8}{\circ}\end{array}$ & & 兽 & & 공 \\
\hline 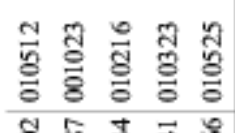 & $\div$ & 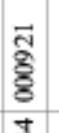 & $\frac{8}{8}$ & 吾 & $\frac{-1}{9}$ & , & $\begin{array}{l}\text { Aิ } \\
\text { : } \\
0\end{array}$ & & 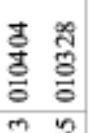 \\
\hline g 5 忢 88 & ' & 志 & 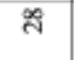 & $\vec{n}$ & $\Xi$ & & 5 & & $m$ \\
\hline 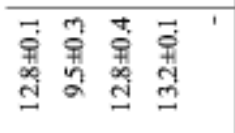 & I & $\begin{array}{l}\overrightarrow{0} \\
\text { in } \\
\text { 至 } \\
=\end{array}$ & 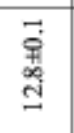 & $\begin{array}{l}\overrightarrow{0} \\
\text { yn } \\
\text { aे } \\
-1\end{array}$ & $\begin{array}{l}\overrightarrow{0} \\
\text { İ⿴囗十 } \\
\text { d }\end{array}$ & & Ồ & & 吾 \\
\hline 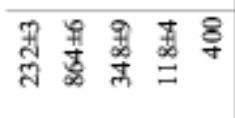 & ' & $\stackrel{\circ}{\subsetneq}$ & $\begin{array}{l}\text { 䓂 } \\
\text { ते }\end{array}$ & 葶 & 苔 & & $\begin{array}{l}\text { तี } \\
\text { 总 } \\
\text { d }\end{array}$ & & 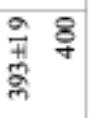 \\
\hline 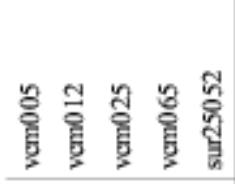 & . & 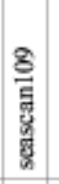 & స్ & 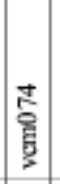 & $\begin{array}{l}\vec{\circ} \\
\overrightarrow{\mathrm{d}} \\
\end{array}$ & $=$ & 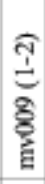 & & 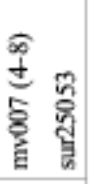 \\
\hline$\stackrel{\circ}{9}$ & ثें & $\dot{q}$ & $\underset{i}{i}$ & $\hat{3}$ & 审 & $\stackrel{\circ}{-}$ & $\because$ & 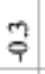 & $\frac{9}{1}$ \\
\hline tे & $\vec{\phi}$ & $\stackrel{\infty}{\rightarrow}$ & $\stackrel{0}{0}$ & $\dot{\hat{q}}$ & ثे & 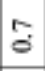 & तิ & $\stackrel{\infty}{\stackrel{\infty}{\varphi}}$ & $\stackrel{1}{+1}$ \\
\hline 声 & $\underset{2}{\pi}$ & F & 茪 & I & 贲 & F & I & 苞 & 正 \\
\hline 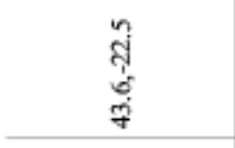 & 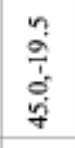 & $\begin{array}{c}2 \\
\infty \\
1 \\
\dot{d} \\
\infty \\
\infty \\
\infty\end{array}$ & $\begin{array}{l}0 \\
\infty \\
\overrightarrow{1} \\
\dot{5} \\
j\end{array}$ & 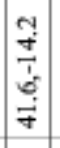 & 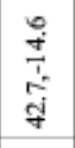 & 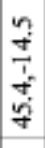 & 견 & 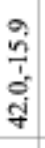 & $\begin{array}{l}\stackrel{0}{+} \\
\stackrel{1}{4} \\
\stackrel{4}{+}\end{array}$ \\
\hline $\begin{array}{l}\text { के } \\
\text { के } \\
\text { के } \\
\text { के }\end{array}$ & 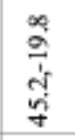 & 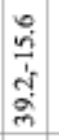 & 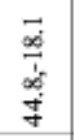 & $\begin{array}{c}2 \\
\stackrel{9}{+} \\
\dot{b} \\
\dot{+}\end{array}$ & 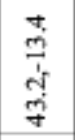 & 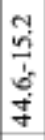 & 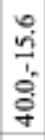 & مि & 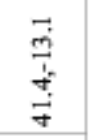 \\
\hline$\frac{8}{0}$ & $\stackrel{8}{0}$ & $\frac{8}{0}$ & $\vec{\delta}$ & $\overrightarrow{\bar{\sigma}}$ & $\stackrel{\circ}{0}$ & $\frac{8}{0}$ & $\frac{8}{0}$ & $\frac{8}{0}$ & $\frac{8}{0}$ \\
\hline 8 & छे & \% & 8 & 8 & $\frac{8}{6}$ & $\frac{8}{0}$ & $\stackrel{8}{0}$ & 8 & है \\
\hline 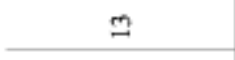 & n & $\bullet$ & 4 & a & $r$ & + & r & ९ & $n$ \\
\hline 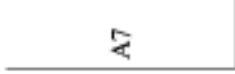 & से & $\frac{9}{4}$ & द & $\frac{\pi}{4}$ & $\frac{3}{4}$ & 4 & $<$ & 2 & दे \\
\hline
\end{tabular}

Table 1a (Contd) 


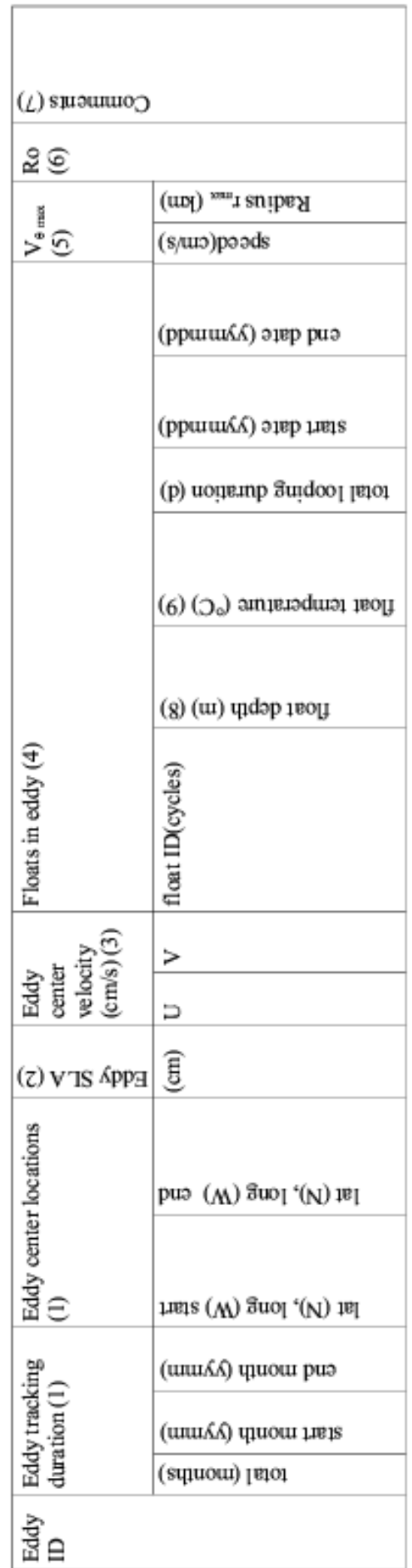

\begin{tabular}{|c|c|c|c|c|c|c|c|c|}
\hline ' $\stackrel{0}{\circ} \stackrel{0}{0}$ & ' & $\stackrel{ \pm}{\stackrel{5}{0}} \stackrel{\infty}{8}$ & $\begin{array}{lll}1 & 1 \\
& & \end{array}$ & $\stackrel{\Xi}{\stackrel{0}{0}}$ & 웅 & $\stackrel{\infty}{\stackrel{0}{0}}$ & 1 & 1 \\
\hline ' & 1 & d $\vec{m}$ & $1 \quad 1 \quad 1$ & $\pi$ त & 응 & y & 1 & ' \\
\hline$\prime^{\prime}= \pm \Omega$ & 1 & $\pm \cong$ & 111 & $a \mathrm{I}$ & A \pm 1 & $a$ & 1 & 1 \\
\hline 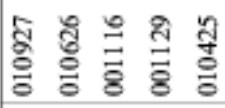 & 1 & స్ & 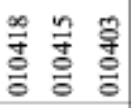 & 응 & 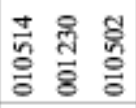 & ํㅗㅇ & 1 & I \\
\hline 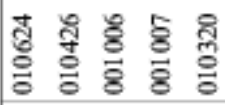 & 1 & 응 흥 & 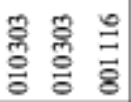 & 웡 & 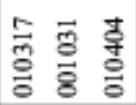 & $\stackrel{\overrightarrow{3}}{\overline{8}}$ & 1 & , \\
\hline स $\vec{\circ}$ \& & ' & 8 శ్తి & ๆ & क & $x$ क त & 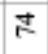 & 1 & ' \\
\hline 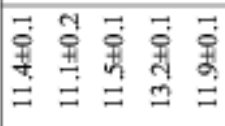 & 1 & 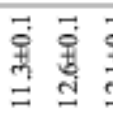 & 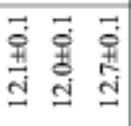 & $\begin{array}{l}\overrightarrow{1} \\
\text { A } \\
= \\
=\end{array}$ & 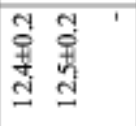 & $\begin{array}{l}\overrightarrow{0} \\
\stackrel{0}{+} \\
\dot{0}\end{array}$ & 1 & 1 \\
\hline 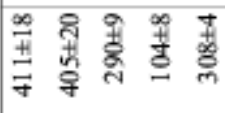 & ' & 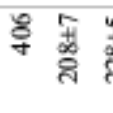 & 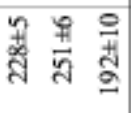 & 音 ₹ิ & 舫 & 寺 & 1 & ' \\
\hline 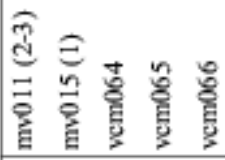 & 1 & 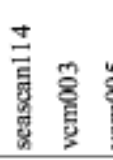 & 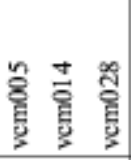 & 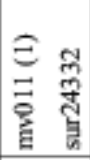 & 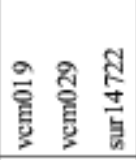 & है & 1 & 1 \\
\hline$\ddot{9}$ & $\overrightarrow{9}$ & & $\stackrel{9}{\varphi}$ & $\overrightarrow{0}$ & $\stackrel{\circ}{8}$ & $\stackrel{\varphi}{\varphi}$ & $\overrightarrow{9}$ & t. \\
\hline$\frac{n}{7}$ & $\frac{n}{1}$ & & $\stackrel{8}{8}$ & $\stackrel{\leftrightarrow}{9}$ & กี & ণิ & $\stackrel{\infty}{\varphi}$ & $\stackrel{9}{7}$ \\
\hline Tै & 武 & & $\frac{7}{4}$ & 苦 & 꼭 & $\frac{7}{4}$ & 者 & $\frac{9}{1}$ \\
\hline ปู & 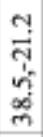 & & 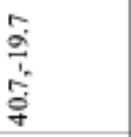 & 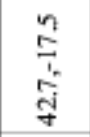 & 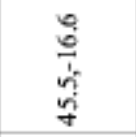 & 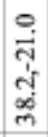 & $\begin{array}{l}\stackrel{a}{y} \\
\text { d. } \\
\text { s. } \\
\dot{+} \\
\dot{y}\end{array}$ & 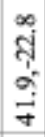 \\
\hline 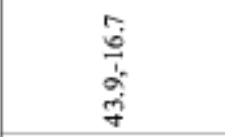 & $\begin{array}{l}9 \\
\infty \\
0 \\
b \\
\infty \\
\infty \\
m\end{array}$ & & 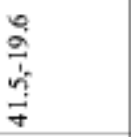 & 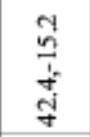 & 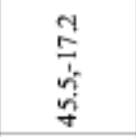 & $\begin{array}{l}0 \\
\frac{0}{2} \\
\stackrel{1}{2} \\
\stackrel{2}{m}\end{array}$ & 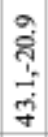 & ָे \\
\hline$\frac{8}{0}$ & $\stackrel{8}{6}$ & & $\frac{8}{5}$ & $\frac{8}{5}$ & $\frac{8}{5}$ & $\frac{8}{0}$ & $\stackrel{8}{0}$ & 훙 \\
\hline 8 & 8 & & 8 & $\stackrel{\circ}{8}$ & $\stackrel{\circ}{8}$ & $\frac{4}{8}$ & 8 & $\stackrel{\circ}{8}$ \\
\hline 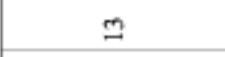 & $\bullet$ & & $=$ & 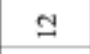 & $\cong$ & $\varrho$ & $a$ & + \\
\hline ช & 0 & & 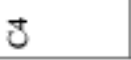 & 3 & 8 & 5 & $\infty$ & $\overrightarrow{0}$ \\
\hline
\end{tabular}

Table 1b 


\begin{tabular}{|c|c|c|c|c|c|c|}
\hline & 递罟 & & & & & 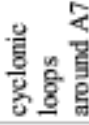 \\
\hline$\stackrel{ \pm}{ \pm}$ & $\stackrel{5}{\circ}$ & 1 & ' & ' & ' & \\
\hline 21 & \pm & ' & ' & ' & ' & \\
\hline$=1$ & 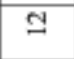 & 1 & 1 & 1 & 1 & \\
\hline 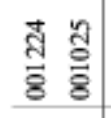 & ণ্ণิ &. &. &. &. & हั \\
\hline $\begin{array}{l}\frac{1}{8} \\
\frac{8}{8} \\
\frac{8}{8}\end{array}$ & $\begin{array}{l}\text { ปิ } \\
\text { है }\end{array}$ & 1 & 1 & 1 &. & $\frac{8}{8}$ \\
\hline$\infty \begin{array}{cc}0 \\
0\end{array}$ & 8 & 1 & ' & ' & ' & 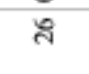 \\
\hline 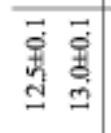 & $\vec{~}$ & 1 & 1 & 1 & 1 & 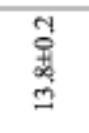 \\
\hline 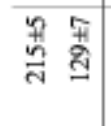 & $\begin{array}{l}\frac{9}{7} \\
6 \\
0\end{array}$ & ' & ' & ' & ' & $\underset{5}{5}$ \\
\hline 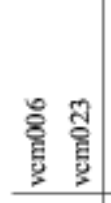 & 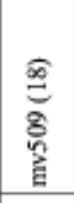 & 1 & , & , & I & $\overrightarrow{\mathrm{s}}$ \\
\hline$\stackrel{\circ}{+}$ & a & 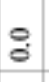 & $\stackrel{n}{q}$ & ฮี & $\dot{9}$ & . \\
\hline તุ & $\overrightarrow{0}$ & $\exists$ & $\frac{7}{1}$ & ? & $\underset{i}{\infty}$ & , \\
\hline 开 & $\frac{7}{7}$ & 计 & 뀨 & $\stackrel{\frac{\pi}{7}}{7}$ & $\frac{9}{7}$ & 1 \\
\hline 椎 & 年 & 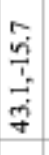 & 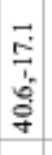 & 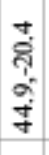 & 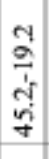 & \\
\hline$\frac{\stackrel{\circ}{\frac{1}{5}}}{\stackrel{+}{+}}$ & 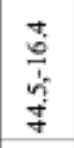 & $\begin{array}{l}\dot{8} \\
\dot{0} \\
\vec{f} \\
\vec{q}\end{array}$ & $\begin{array}{l}\overrightarrow{2} \\
\overrightarrow{7} \\
\vec{b} \\
\overrightarrow{+}\end{array}$ & 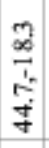 & 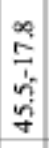 & 1 \\
\hline $\overrightarrow{8}$ & $\stackrel{8}{\circ}$ & $\frac{8}{5}$ & $\frac{8}{5}$ & $\frac{8}{6}$ & $\frac{8}{5}$ & \\
\hline$\stackrel{\circ}{8}$ & $\overrightarrow{\overrightarrow{8}}$ & $\frac{8}{5}$ & $\frac{2}{8}$ & $\begin{array}{l}\stackrel{8}{8} \\
b \\
\end{array}$ & $\frac{8}{5}$ & 1 \\
\hline $\mathrm{A}$ & n & $\mathrm{N}$ & 9 & in & $\mathrm{m}$ & 1 \\
\hline $\overrightarrow{\tilde{u}}$ & ปี & $\overrightarrow{0}$ & 0 & 0 & 0 & కే̊ํㄹ \\
\hline
\end{tabular}

Table 1b (Contd) 


\section{Table captions}

Table 1 (a) (b): Identified eddies characteristics summary: (a) Anticyclones, (b) Cyclones.

Explanation notes:

(1) Eddy tracking duration and locations are derived from the combined altimetry-Lagrangian analysis.

(2) Filtered SLA estimated at location of eddy center (in $\mathrm{cm}$ ). Standard deviation during tracking is given.

(3) Eddy center velocities (east component U, north component $\mathrm{V}$ ) in $\mathrm{cm} / \mathrm{s}$, are means estimated over the whole eddy tracking duration.

(4) Floats trapped for at least 2 loops in the corresponding eddy («mv »: Marvor floats; « seascan » and « Sv »: Rafos floats; « vem »: VCM floats; « sur »: Surdrift type drifting buoys). For Marvor floats, corresponding cycle numbers are given between parentheses.

(5) $\mathrm{V}_{\theta \max }$ indicates the maximum azimuthal velocity averaged over one loop (in $\mathrm{cm} / \mathrm{s}$ ), and the corresponding mean distance $r_{\max }$ from eddy center (in $\mathrm{km}$ ). When looping duration was too short, analysis was not completed.

(6) Ro is the Rossby number, estimated as $2 V_{\theta \max } / \mathrm{fr}_{\max }$, from the track of the corresponding float.

(7) Additional comments: «NE», « $\mathrm{NW} »$ and $« \mathrm{~S} »$ respectively mean «northeast», « northwest » and « south », and « $\mathrm{AC} »$ and « $\mathrm{CY} », ~ «$ anticyclone » and « cyclone ».

(8) Mean float depth over the looping duration is given in m. For Surdrift type buoys, nominal drogue depth $(400 \mathrm{~m})$ is given. Standard deviation over the mentioned record is given. For Seascan type rafos floats, depth is estimated (see text), and no standard deviation can be computed.

(9) Mean float temperature $\left({ }^{\circ} \mathrm{C}\right)$ and standard deviation over looping period.

(10) CA7 is a small cyclone looping anticyclonically around A7, and was not seen on altimetry data. 


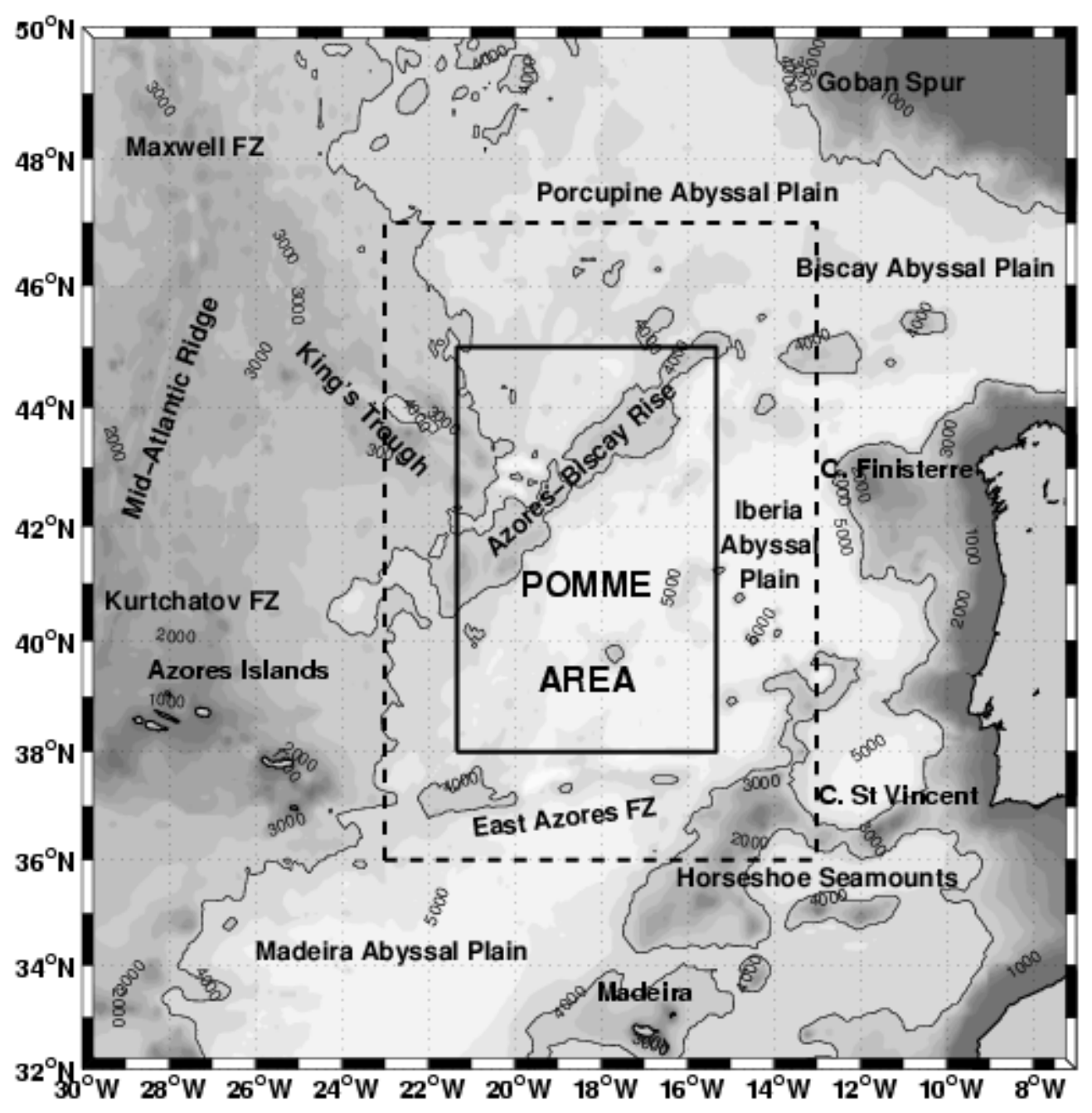

Figure 1

General map of the study area. Major topographic features are labelled. Topography (ETOPO5) is gray-shaded with $500 \mathrm{~m}$ shade intervals and the $4000 \mathrm{~m}$ isobath is plotted as a solid line. The «POMME area » is overlaid as a solid line rectangle, and the «study area » as a dashed line rectangle. 


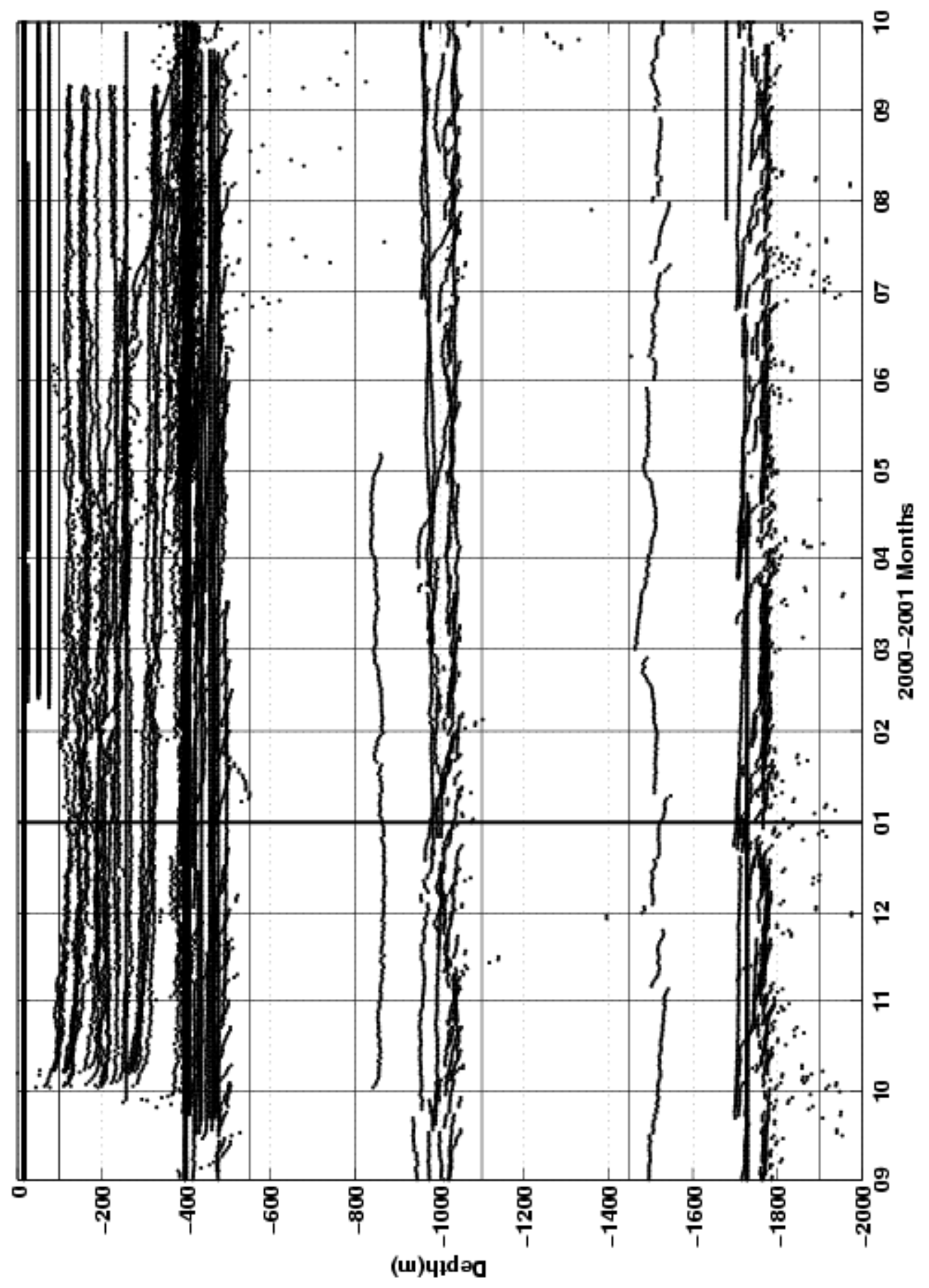

Figure 2

Time (months) - depth (m) distribution of the whole POMME Lagrangian dataset. Several « pressure instabilities » that affected Marvor floats are visible as individual dots scattered between the lines. 


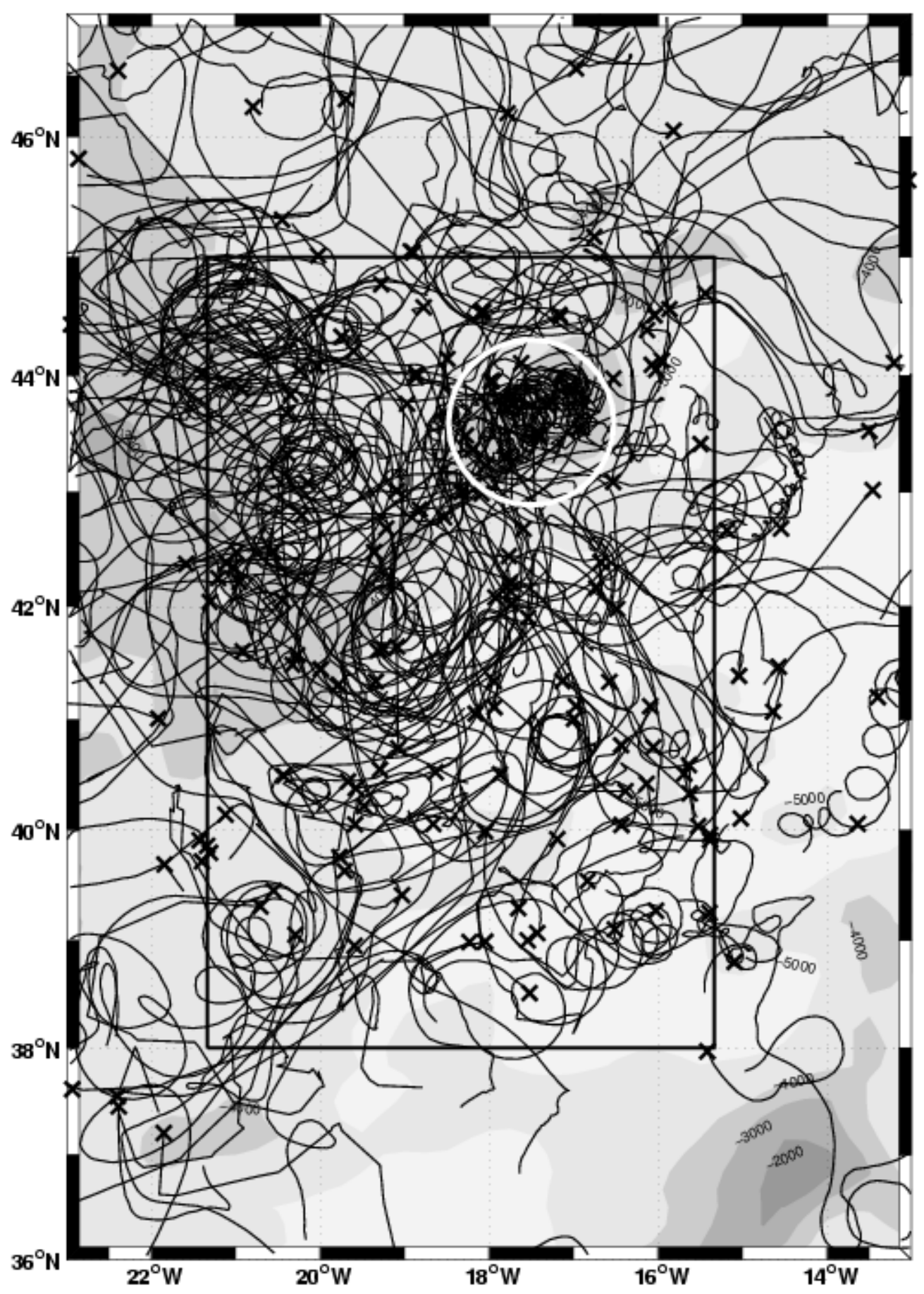

Figure 3a

Lagrangian tracks of the POMME drifters and floats from September 2000 to September 2001 in the 100 - $550 \mathrm{~m}$ layer. Crosses indicate the beginning of the tracks (or track segments in the case of Marvor floats). Smoothed topography is represented as gray shades, in $1000 \mathrm{~m}$ depth ranges, and depths contours are indicated. The «POMME area » is overlaid as a solid line rectangle. Mean position of anticyclone A1 is indicated as a white circle. 


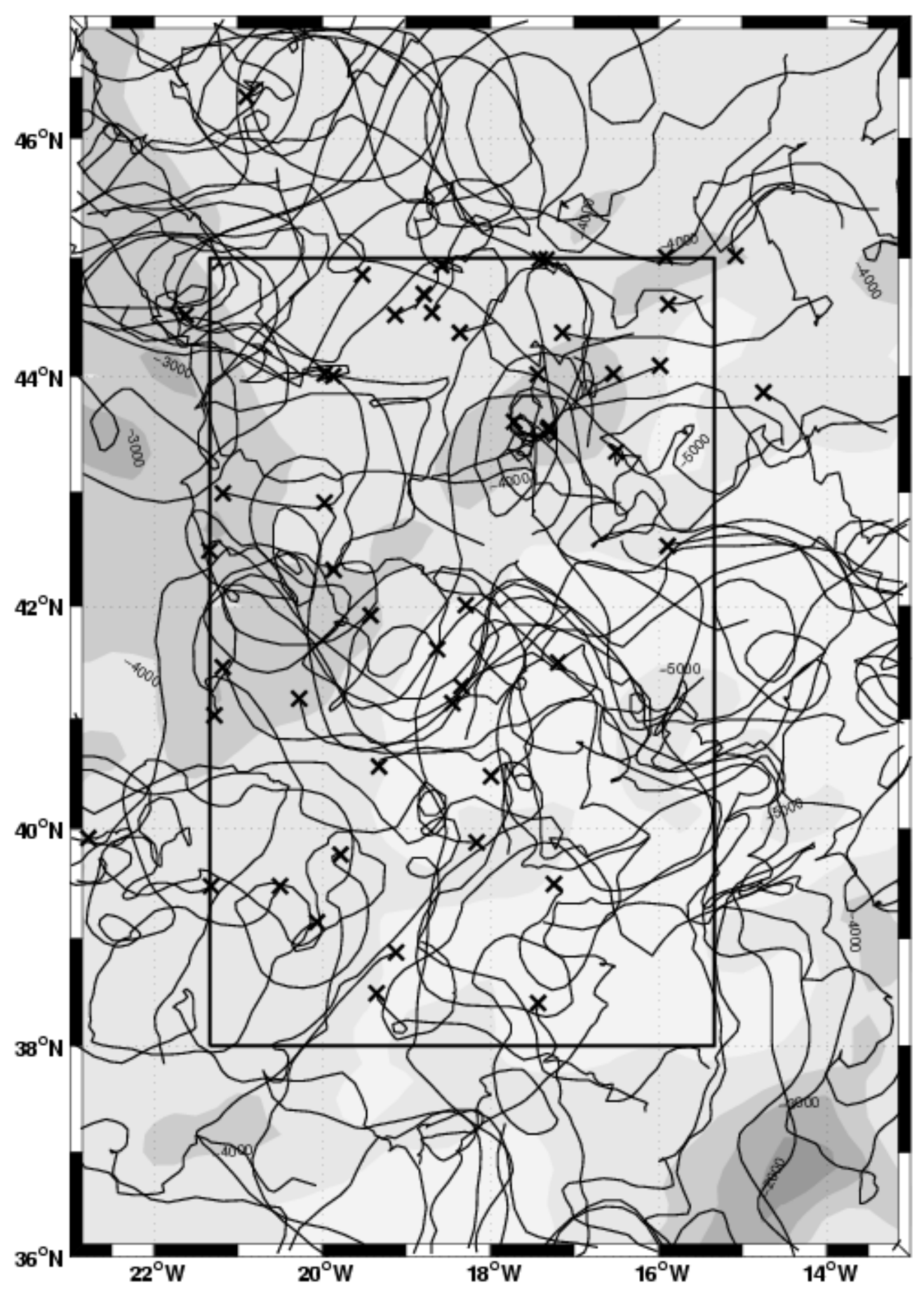

Figure $3 b$

Lagrangian tracks of the POMME drifters and floats from September 2000 to September 2001 in the $0-100 \mathrm{~m}$ layer. Crosses indicate the beginning of the tracks. Smoothed topography is represented as gray shades, in $1000 \mathrm{~m}$ depth ranges, and depths contours are indicated. The «POMME area » is overlaid as a solid line rectangle. 


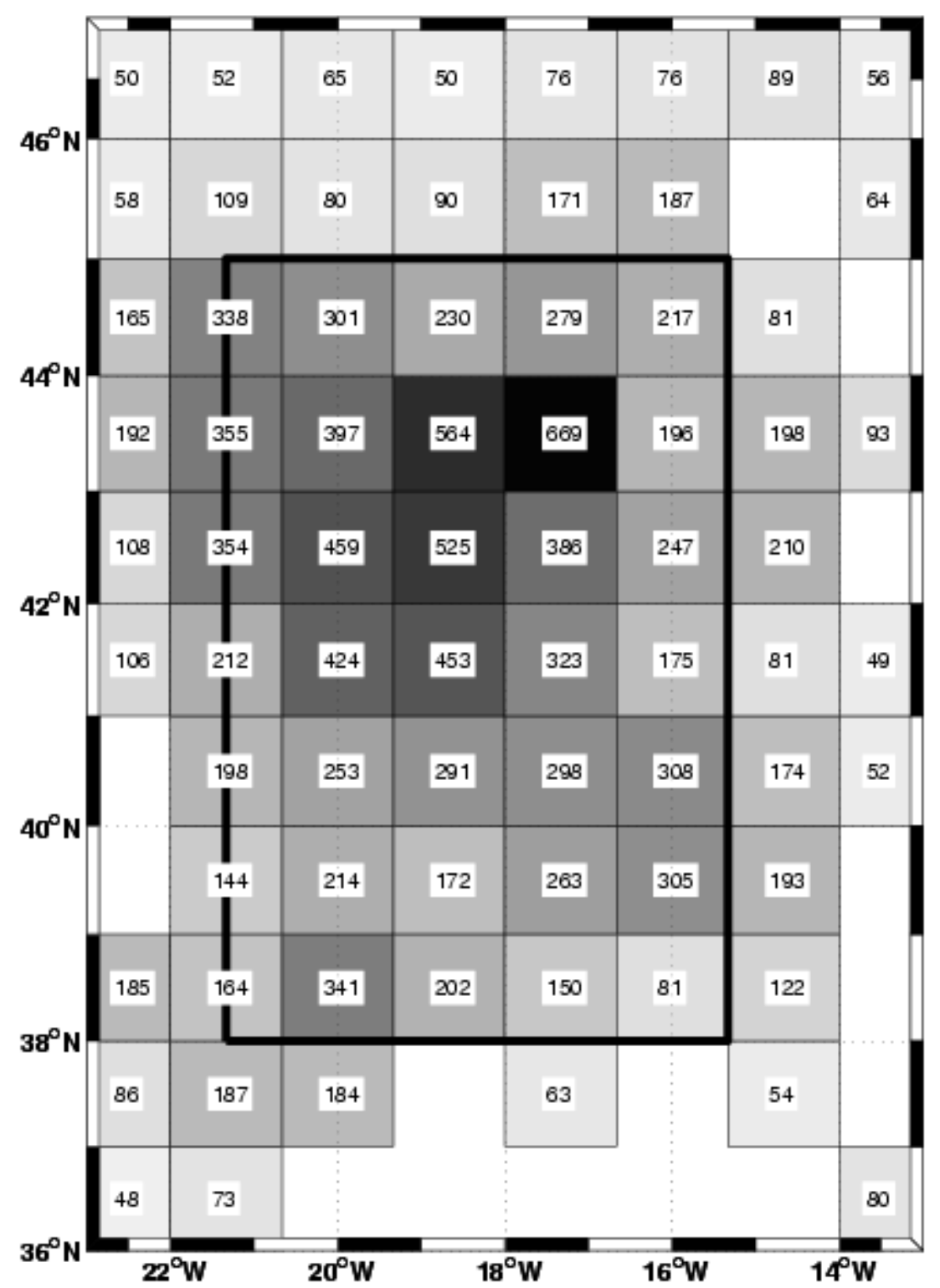

Num ber of days

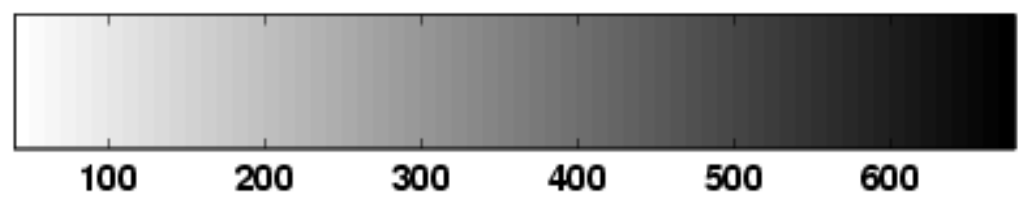

Figure 4a

Lagrangian data distribution (in float-days) in $1^{\circ}$ latitude $\mathrm{x} 1^{\circ} 20^{\prime}$ longitude boxes for the period September 2000 - September 2001 in the 100 - 550 m layer. A minimum threshold of 10 times the average Lagrangian timescale was used (minimum number of days 45 - maximum number of days 669 ). Number of days is given in each box and color-coded according to gray shaded colorbar. 


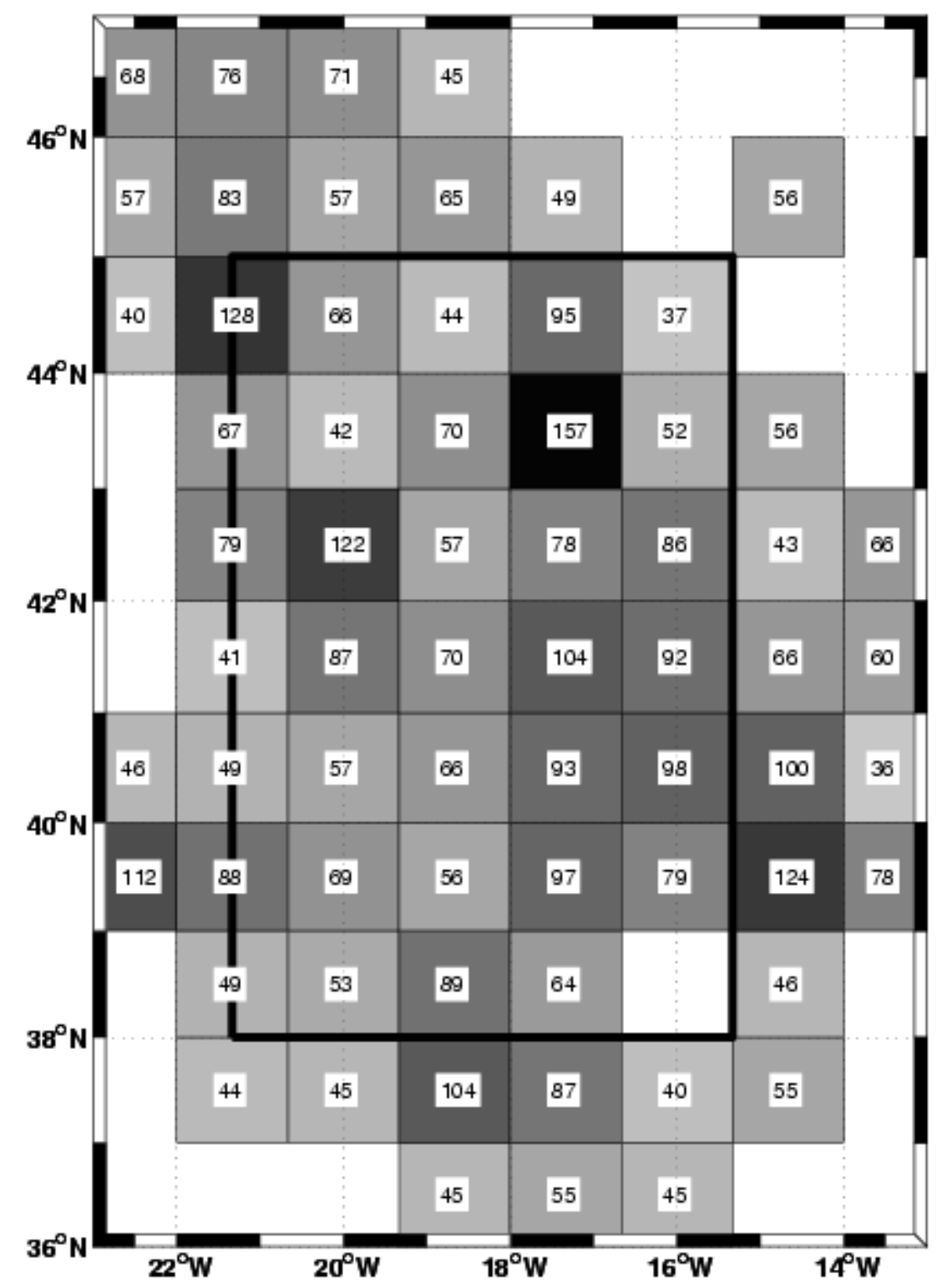

Number of days

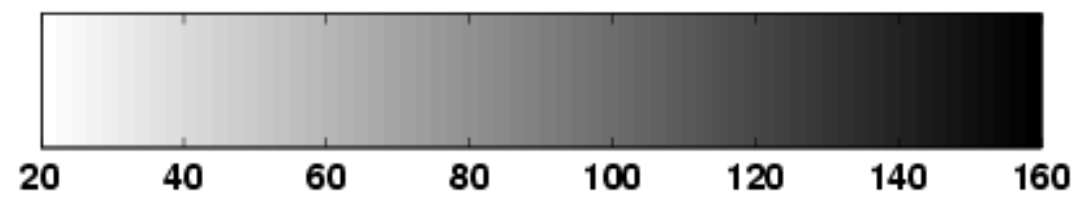

Figure $4 b$

Lagrangian data distribution (in float-days) in $1^{\circ}$ latitude $\mathrm{x} 1^{\circ} 20^{\prime}$ longitude boxes for the period September 2000 - September 2001 in the 0 - 100 m layer. A minimum threshold of 10 times the average Lagrangian timescale was used (minimum number of days 35 - maximum number of days 157 ). Number of days is given in each box and color-coded according to gray shaded colorbar. 


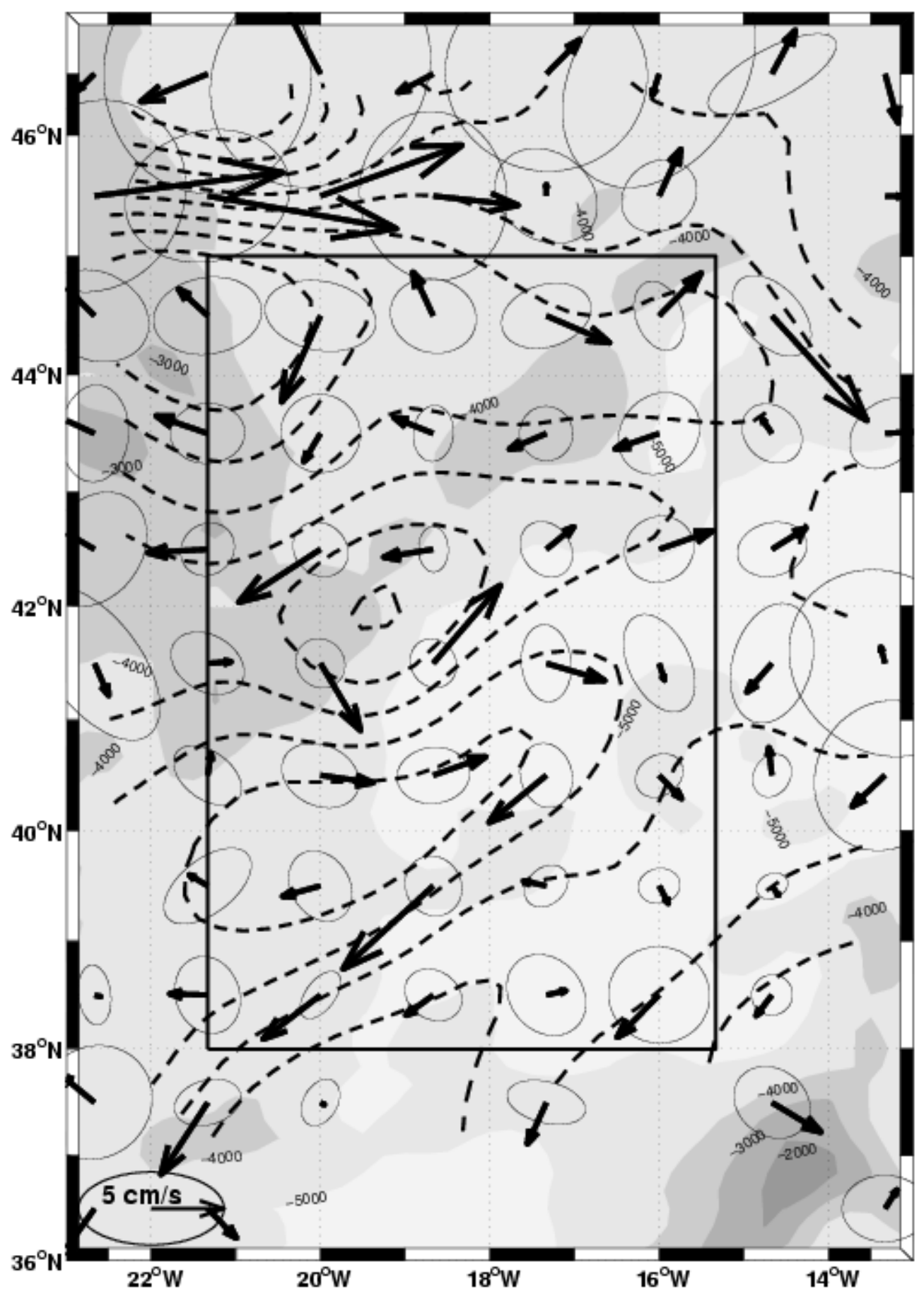

Figure 5a

Mean currents derived from Lagrangian data in $1^{\circ}$ latitude $\mathrm{x} 1^{\circ} 20^{\prime}$ longitude boxes for the period September 2000 - September 2001 in the 100 - 550 m layer. Error ellipses are plotted. A minimum threshold of 10 times the average Lagrangian timescale for each layer is used. A velocity scale is plotted. Smoothed deep topography is represented as in Figure 3. Dashed lines represent streamfunction derived from Objective Analysis (see text): Contour intervals are $1500 \mathrm{~m}^{2} / \mathrm{s}$. 


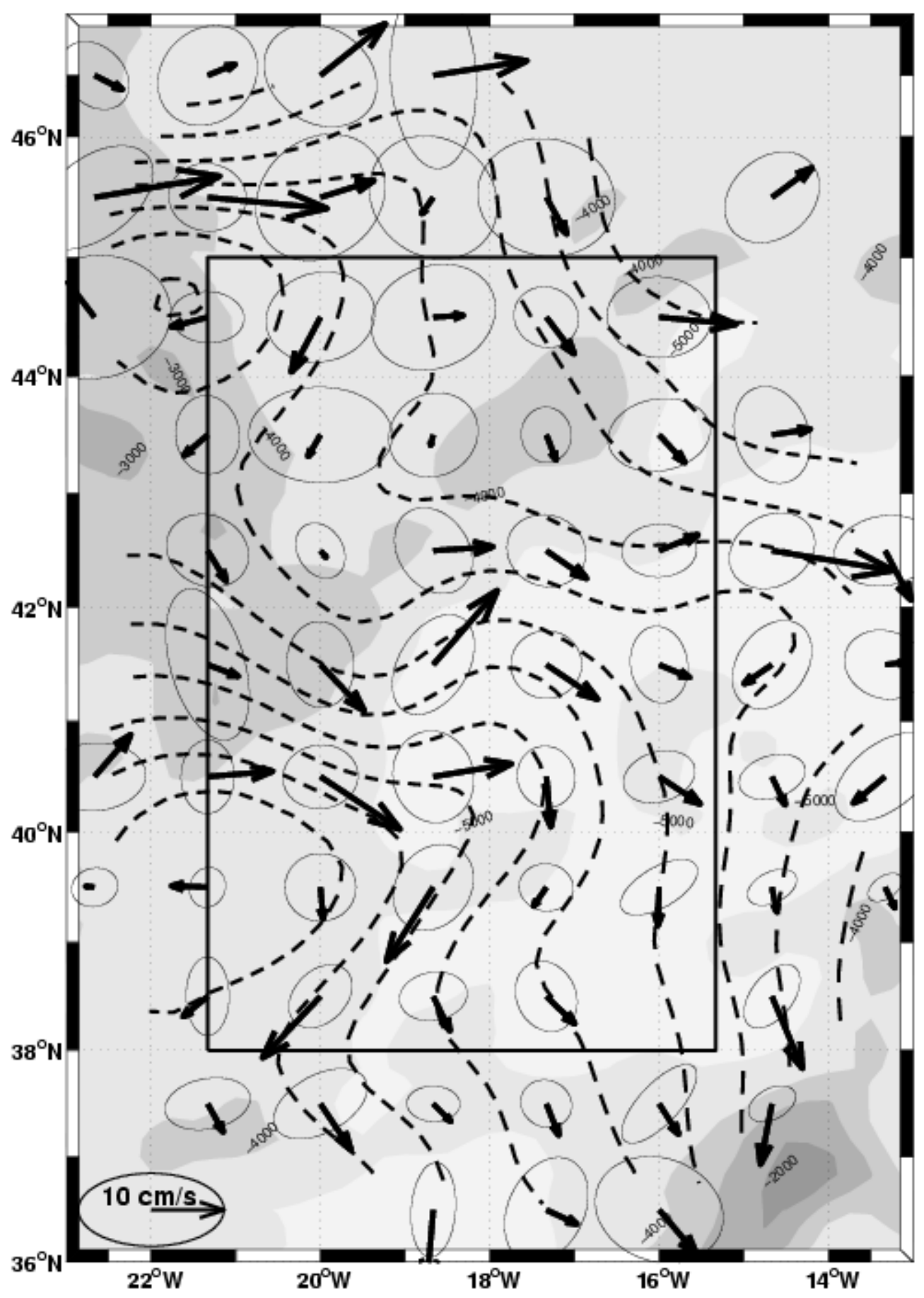

Figure $5 b$

Mean currents derived from Lagrangian data in $1^{\circ}$ latitude $\mathrm{x} 1^{\circ} 20^{\prime}$ longitude boxes for the period September 2000 - September 2001 in the 0 - 100 m layer. Error ellipses are plotted. A minimum threshold of 10 times the average Lagrangian timescale for each layer is used. A velocity scale is plotted. Smoothed deep topography is represented as in Figure 3. Dashed lines represent streamfunction derived from Objective Analysis (see text): Contour intervals are $3000 \mathrm{~m}^{2} / \mathrm{s}$. 


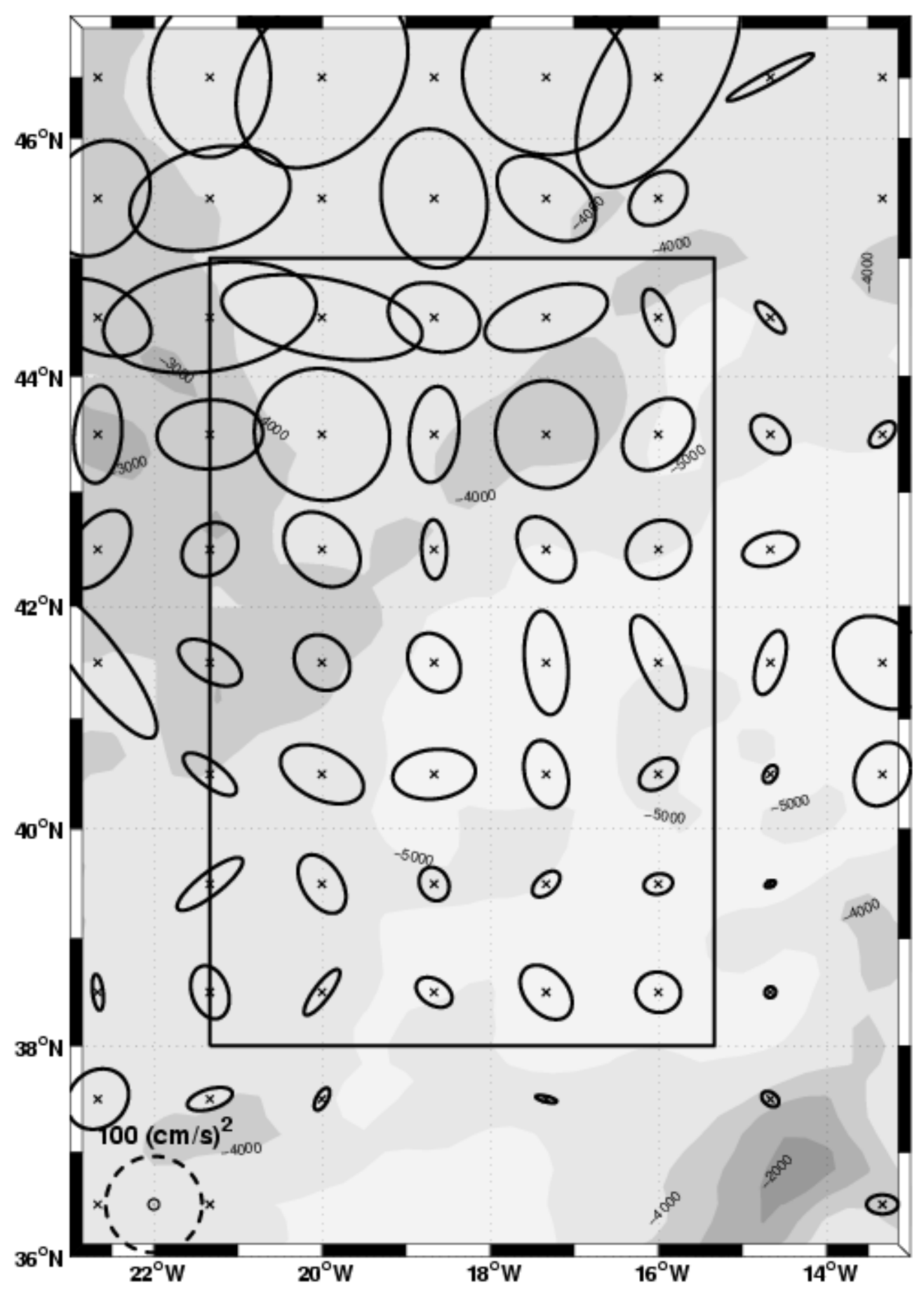

Figure 6a

Velocity variance ellipses derived from Lagrangian data in $1^{\circ}$ latitude x $1^{\circ} 20^{\prime}$ longitude boxes for the period September 2000 - September 2001 in the $100-550 \mathrm{~m}$ layer. EKE is equal to the arithmetic mean of the principal axes. The scale, at the bottom left, represents a variance circle with radius of mentioned value. A minimum threshold of 10 times the average Lagrangian timescale is used. Topography is represented as in Figure 3. 


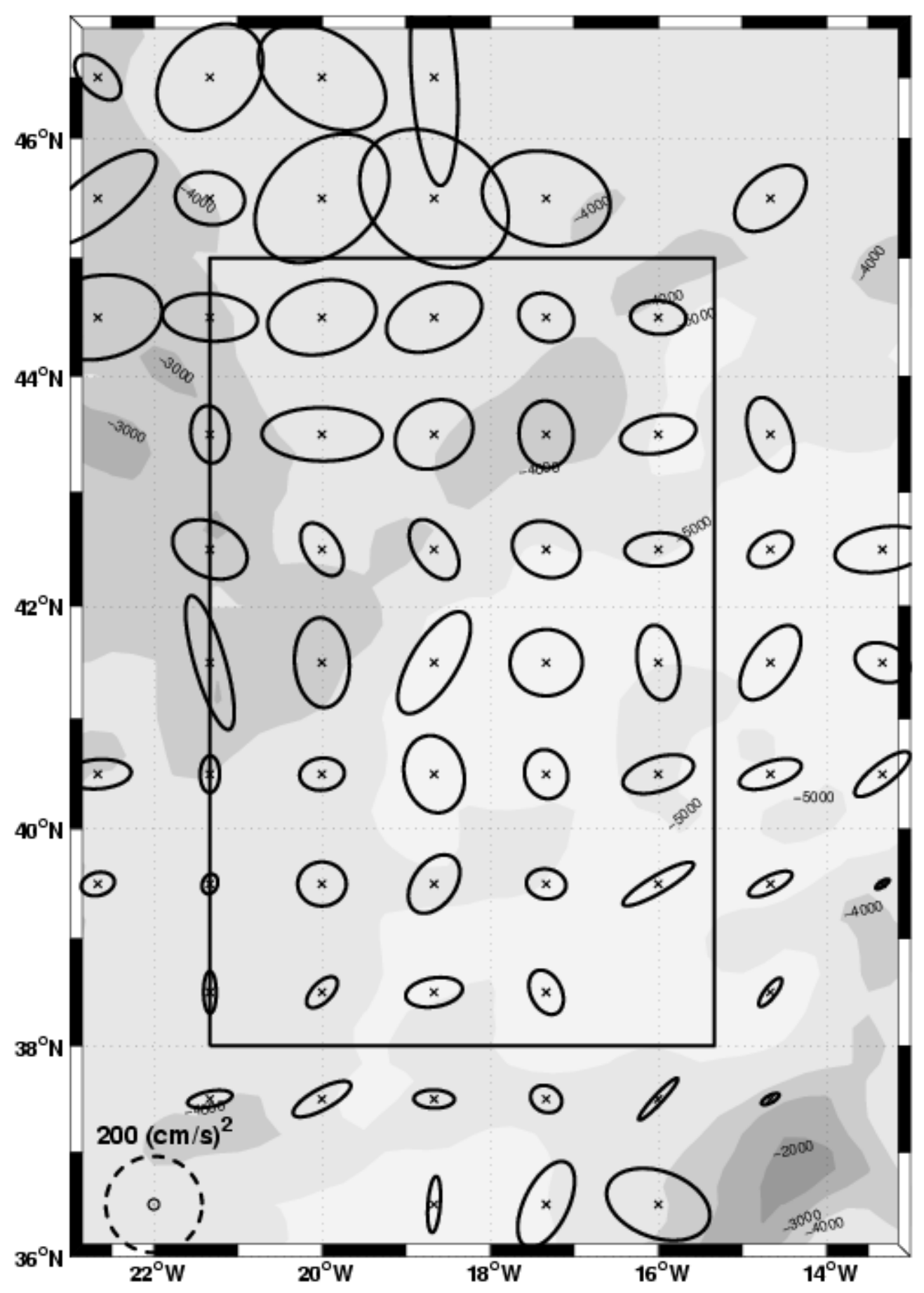

Figure $6 b$

Velocity variance ellipses derived from Lagrangian data in $1^{\circ}$ latitude x $1^{\circ} 20^{\prime}$ longitude boxes for the period September 2000 - September 2001 in the $0-100 \mathrm{~m}$ layer. EKE is equal to the arithmetic mean of the principal axes. The scale, at the bottom left, represents a variance circle with radius of mentioned value. A minimum threshold of 10 times the average Lagrangian timescale is used. Topography is represented as in Figure 3. 


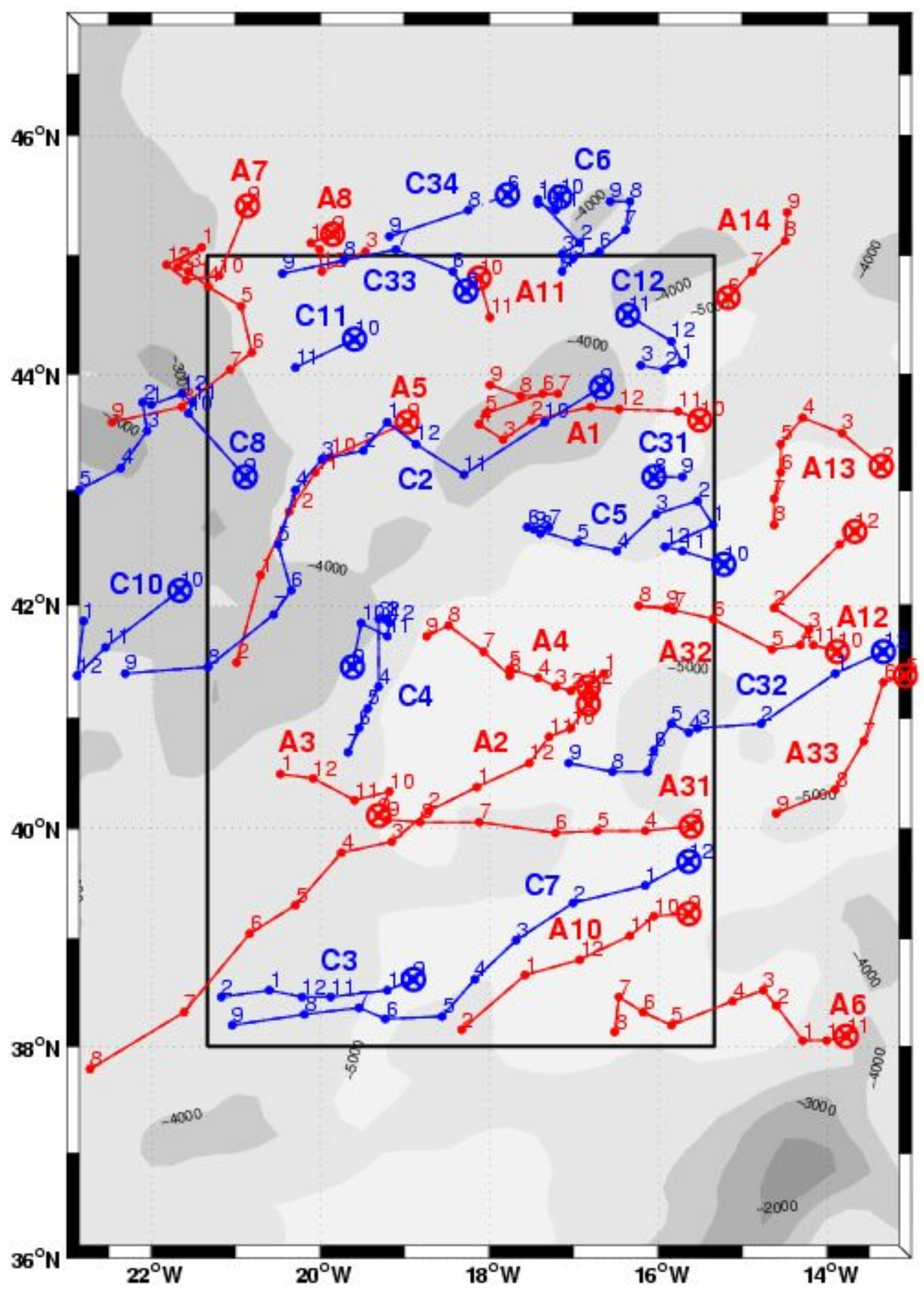

Figure 7

Monthly trajectories of eddy centers determined from combined Lagrangian - altimetry data. Anticyclone $(« \mathrm{~A} »)$ (cyclone $(« \mathrm{C} »))$ tracks are in red (blue). Labels identify eddies near their trajectories. Dots indicate mid-month eddy positions during the period September 2000 - September 2001. 2000-2001 months are labelled along the tracks. Topography is represented as in Figure 3. 


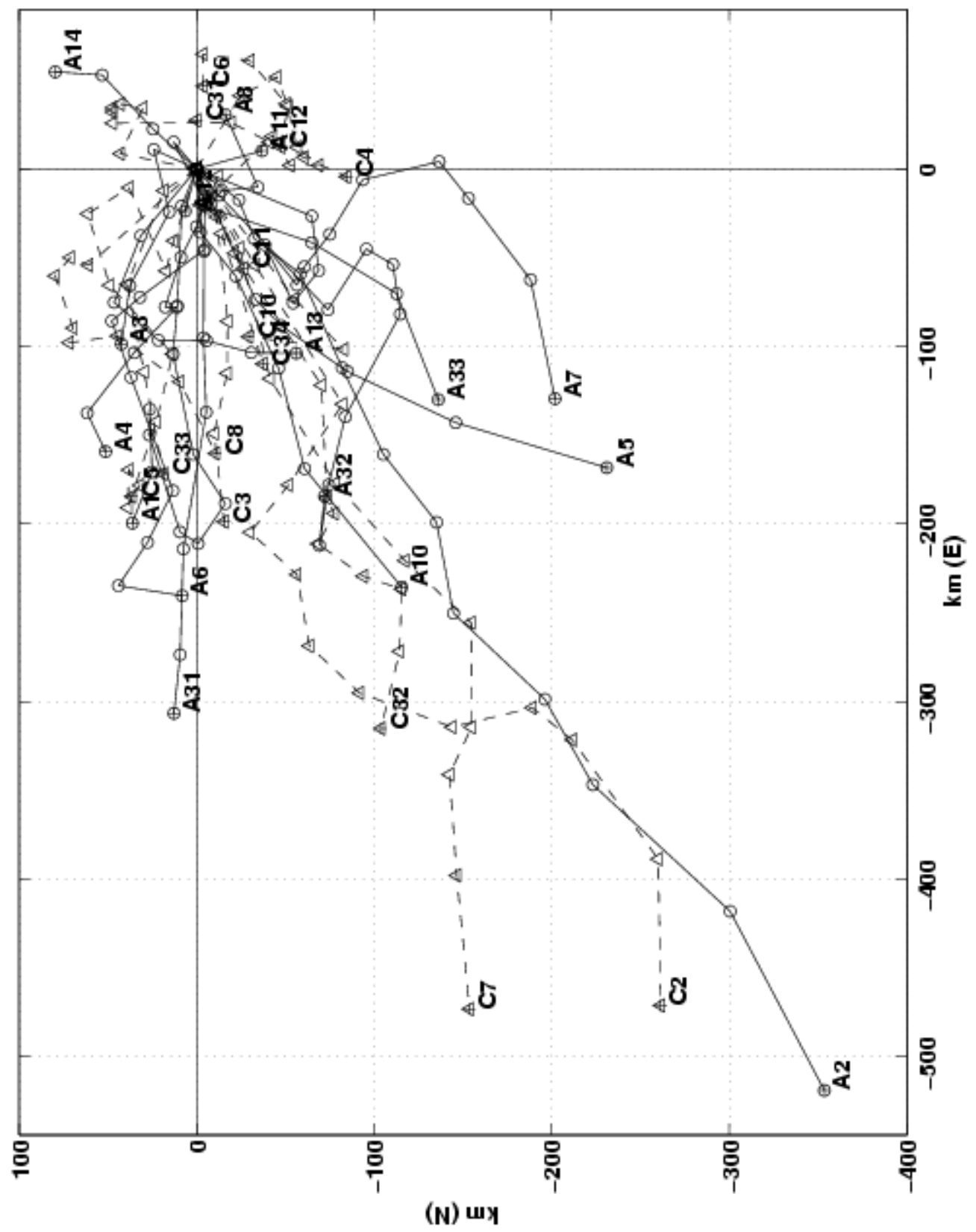

Figure 8

Eddy center trajectories relative to their initial detected position during the period September 2000 - September 2001. 2000-2001 mid-month positions (labelled) are plotted for anticyclones (solid line; open circles) and cyclones (dashed line; open triangles). Eddies are labelled at the end of their relative tracks. East and North positions are given in $\mathrm{km}$. 


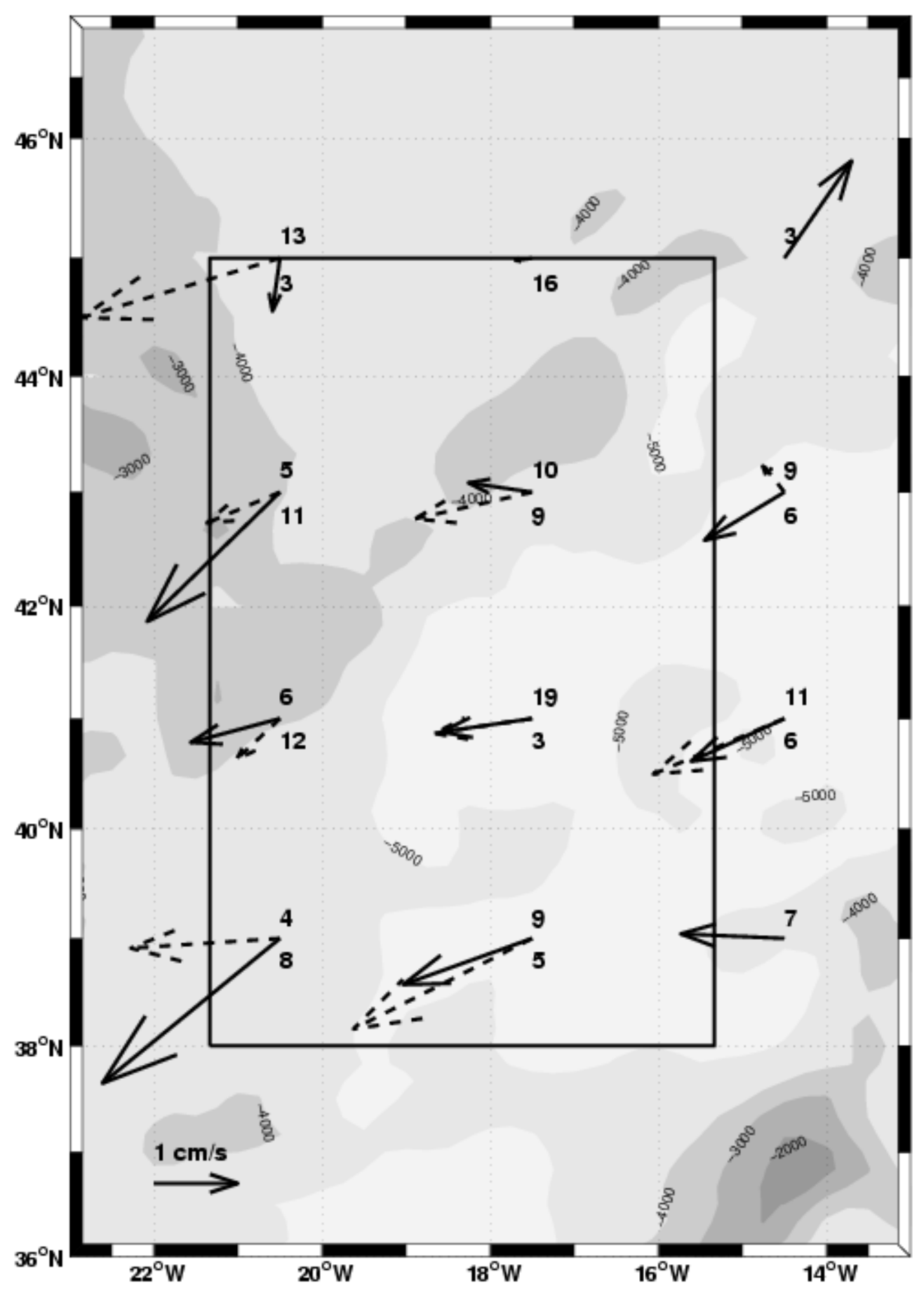

Figure 9

Eddy center velocities binned in $2^{\circ}$ latitude $\mathrm{x} 3^{\circ}$ longitude boxes for the period September 2000 - September 2001. Anticyclone arrows are plotted as solid lines, cyclones arrows are dashed. The number at the base of the arrows (upper: anticyclone; lower: cyclones) indicate the number of monthly vectors used in the estimation (a minimum threshold of 3 months was used). A velocity scale $(1 \mathrm{~cm} / \mathrm{s})$ is plotted. Topography is represented as in Figure 3. 


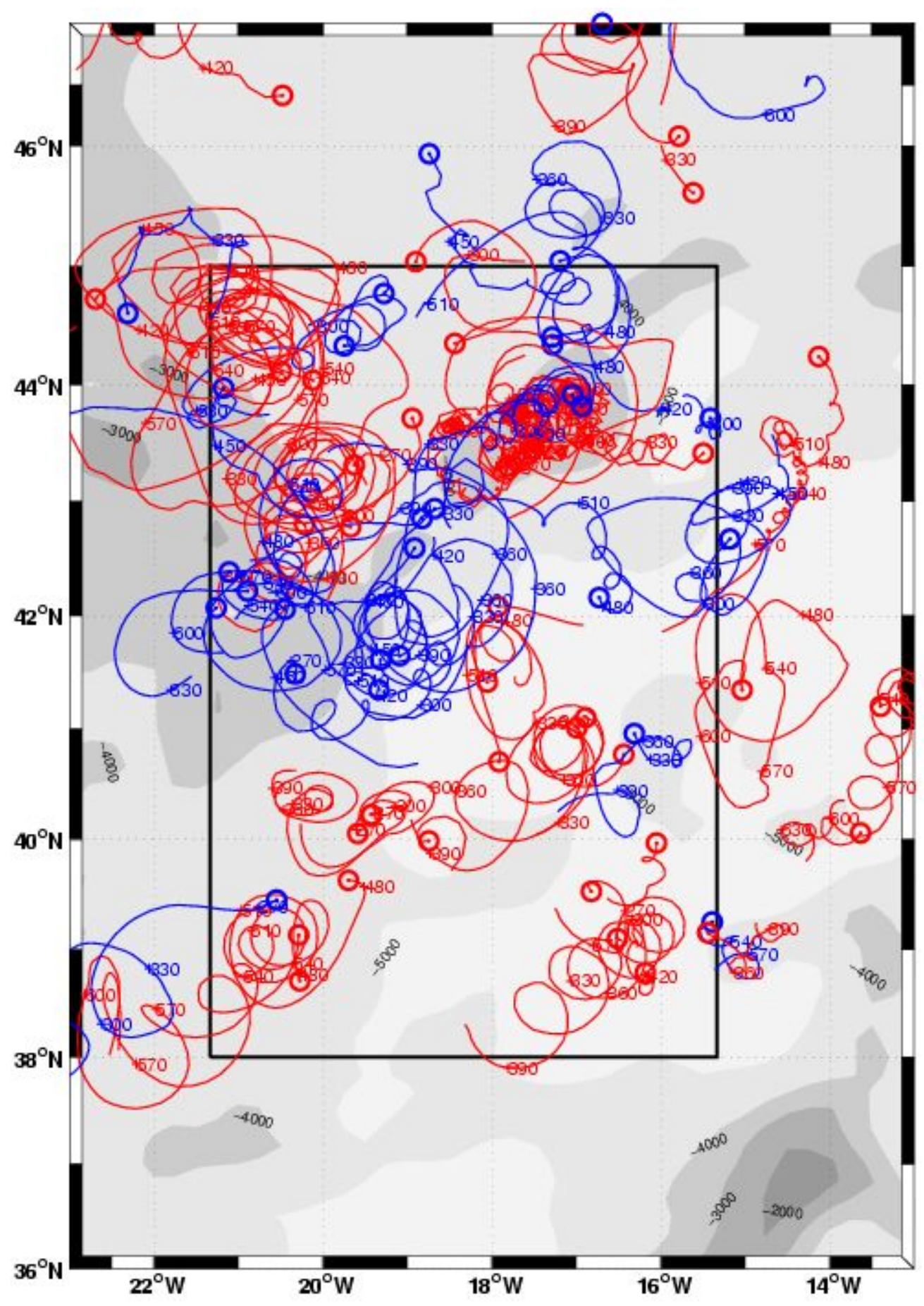

Figure 10

Looping float trajectories in the 100 - 550 m layer, during the period September 2000 September 2001. Selected floats made at least two consecutive loops in the same direction. Anticyclonic (cyclonic) tracks are in red (blue). First underwater float position is indicated as an open circle. Gaps in trajectories are due to the surface phase of Marvor floats. Day number (from 01/01/2000) is labelled every 30 days along the tracks. Topography is represented as in Figure 3. 

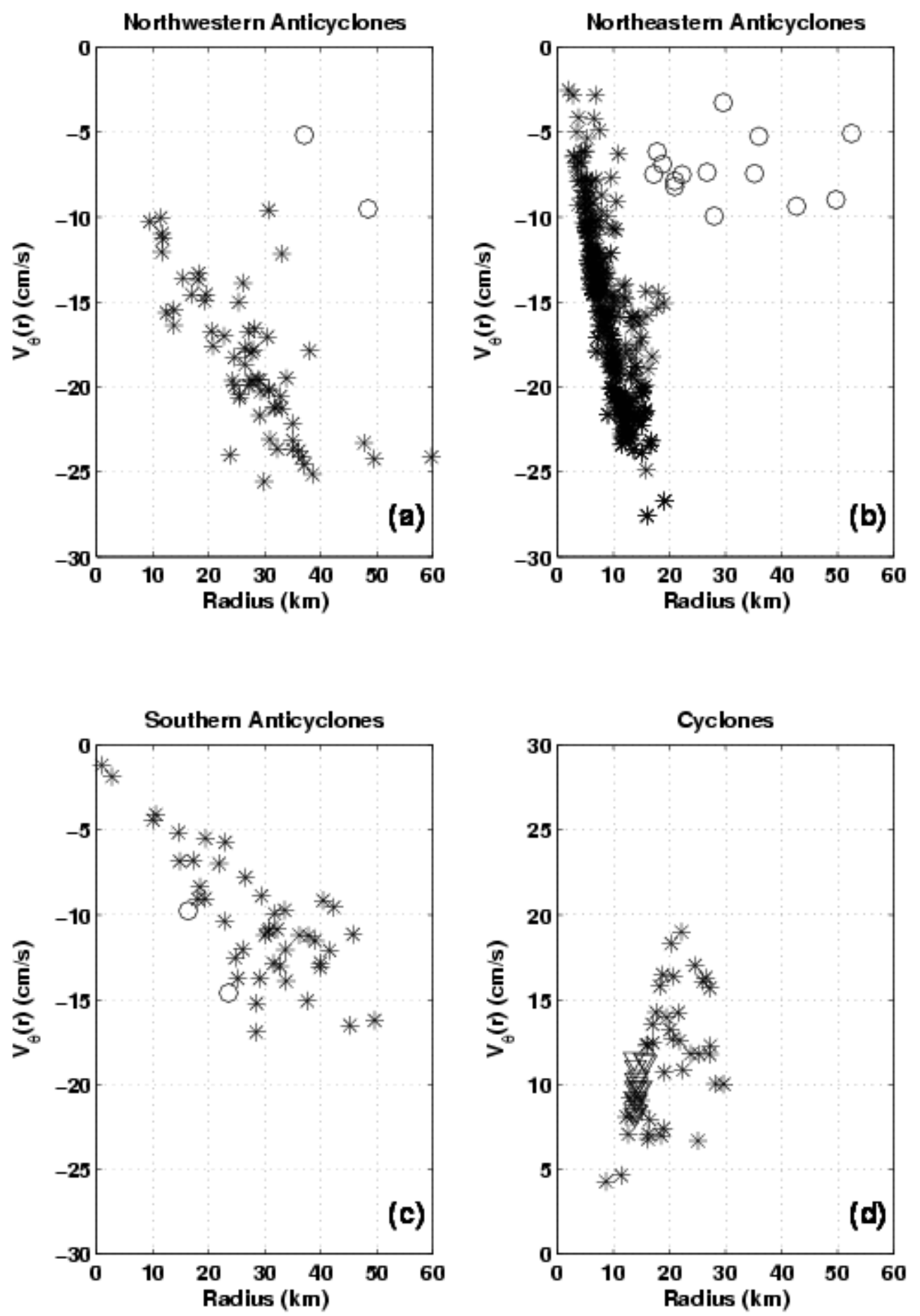

Figure 11

Eddy azimuthal velocities $(\mathrm{cm} / \mathrm{s})$ as a function of distance $(\mathrm{km})$ from eddy center. a) Northwestern (A5, A7 and an unnamed anticyclone), b) northeastern (A1, A13), c) southern (A2, A3, A10) anticyclones and d) cyclones $(\mathrm{C} 2, \mathrm{C} 4, \mathrm{C} 5, \mathrm{C} 11, \mathrm{C} 12)$ are distinguished (see text). Estimations are for the 100 - $550 \mathrm{~m}$ layer (stars), the 800 - $1100 \mathrm{~m}$ layer (open circles) and the 1700-1800 m layer (downward triangles). 

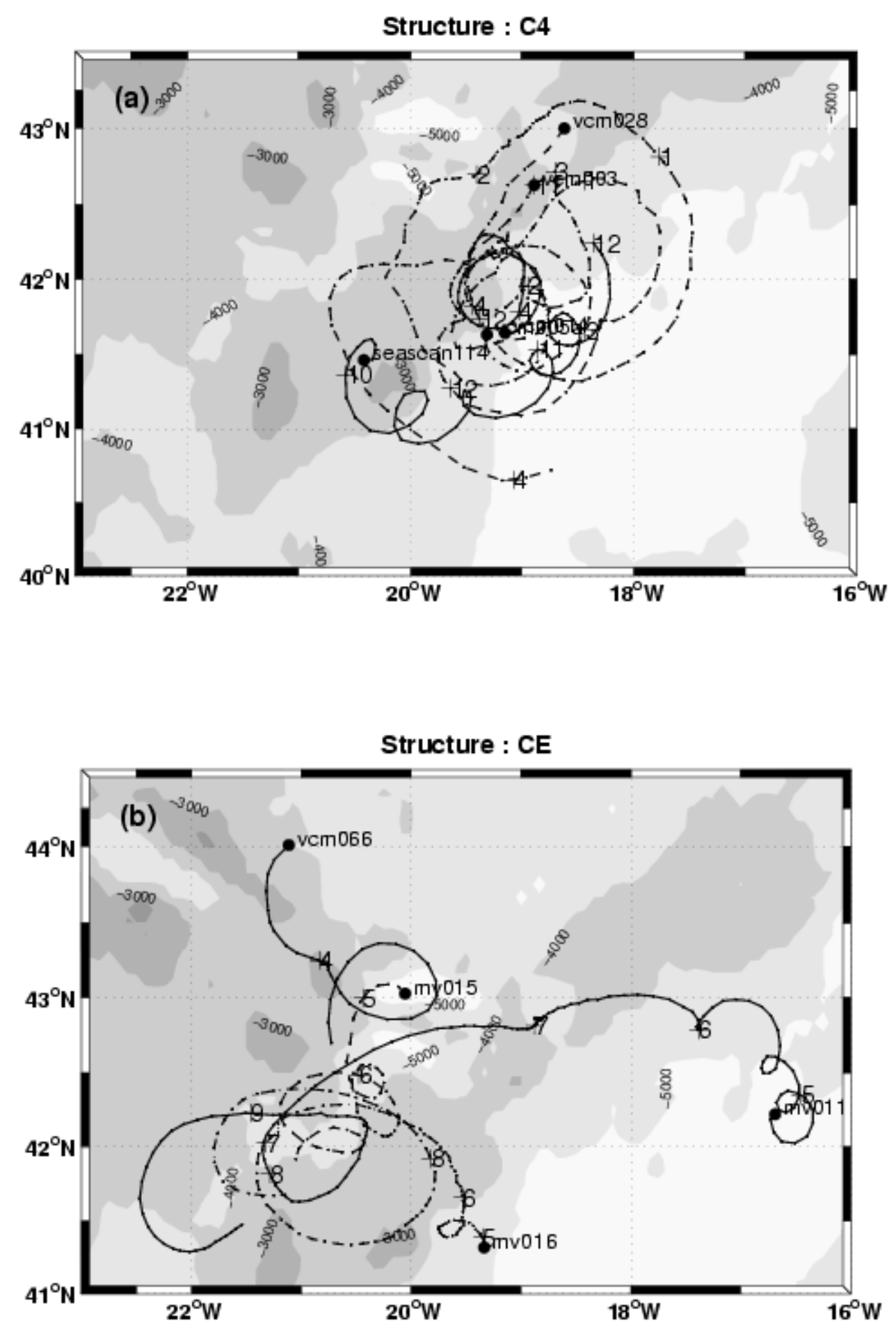

Figure 12

Selected trajectories for cyclonic eddies. All floats are in 100 - 550 m layer. a) Cyclone C4; b) «Cyclonic exchange » («CE ») (see text). Float identification is plotted at start of trajectory, marked by a filled dot. Solid, dashed and dashed dot lines are used to distinguish between trajectories. Months are indicated along trajectories, as labelled crosses. Topography is represented as gray shades, in $1000 \mathrm{~m}$ depth ranges, and depths contours are indicated. 

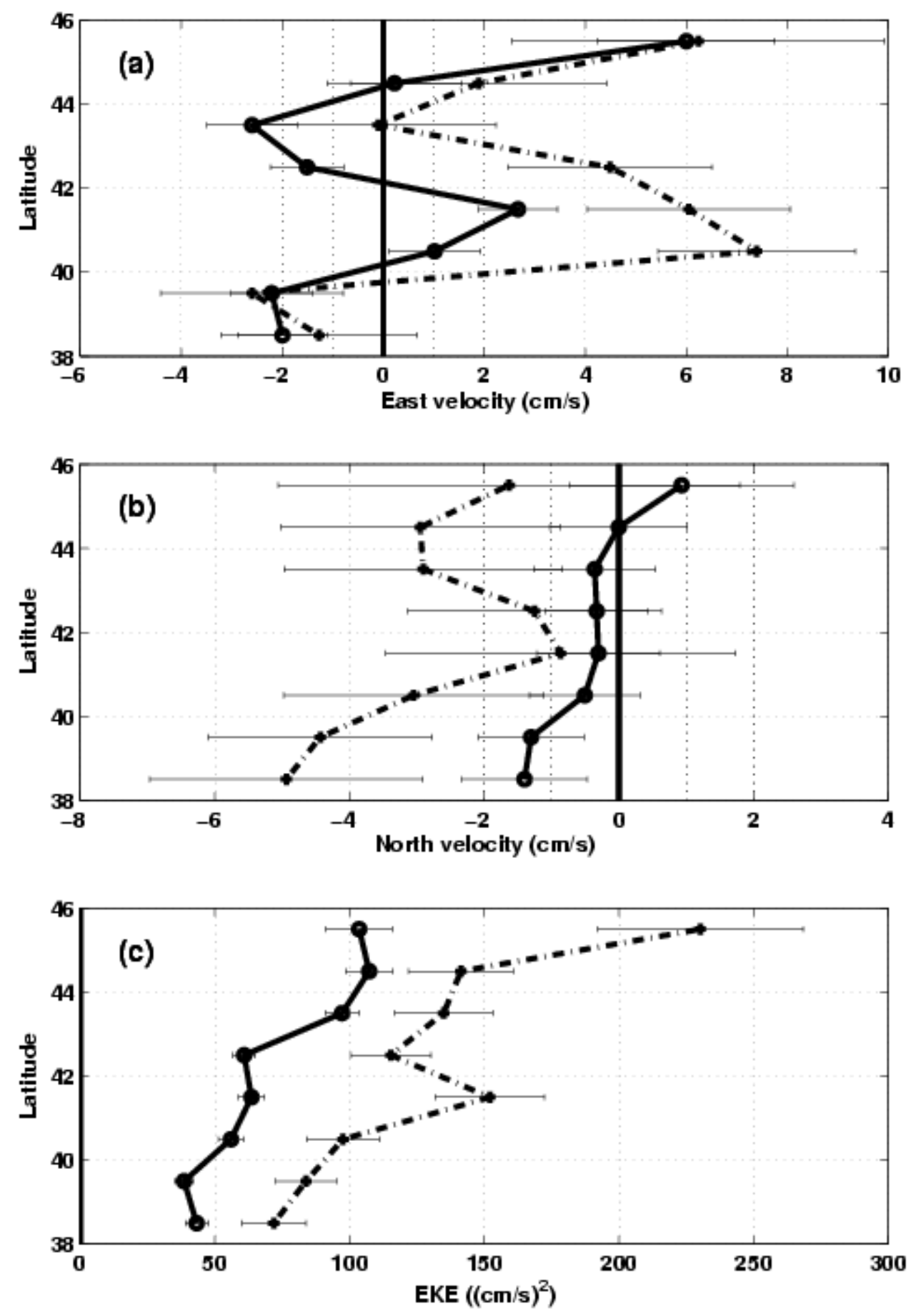

Figure 13

Zonally averaged float velocities and EKE as a function of latitude for the period September 2000 - September 2001 . All quantities are zonally averaged over longitudes $22^{\circ}-15^{\circ} 20^{\prime} \mathrm{W}$. Solid lines are for the $100-550 \mathrm{~m}$ layer, and dash-dotted lines for the $0-100 \mathrm{~m}$ layer. a) east velocities $(\mathrm{cm} / \mathrm{s})$, b) north velocities $(\mathrm{cm} / \mathrm{s})$ and c) EKE $\left((\mathrm{cm} / \mathrm{s})^{2}\right)$. In each case, we have averaged over the box data of Figures 5 and 6. Standard deviations are plotted as error bars. 

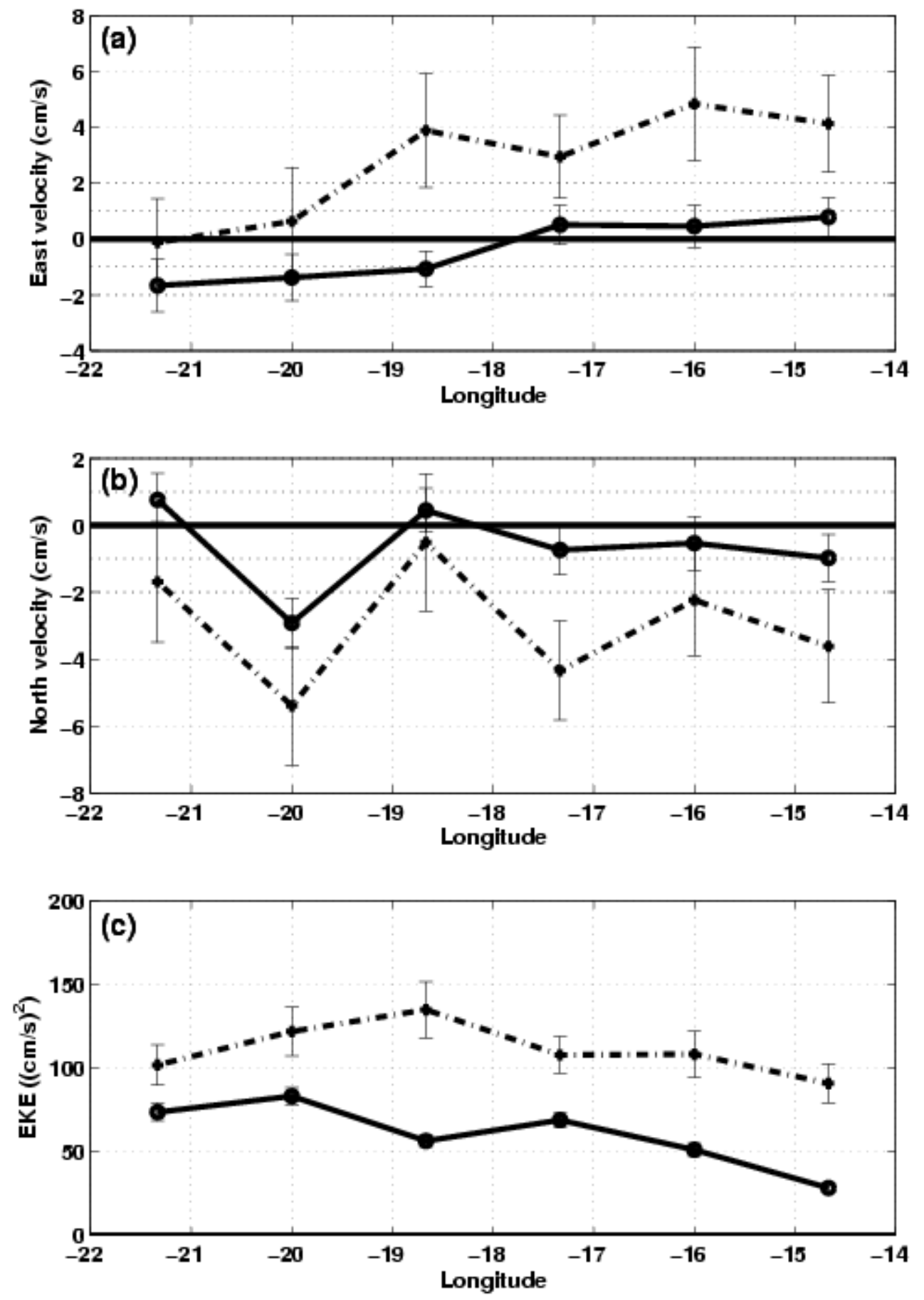

Figure 14

Meridionally averaged float velocities and EKE as a function of longitude for the period September 2000 - September 2001. All quantities are meridionally averaged over latitudes $38^{\circ}-46^{\circ}$ N. Solid lines are for the $100-550 \mathrm{~m}$ layer, and dash-dotted lines for the $0-100 \mathrm{~m}$ layer. a) east velocities $(\mathrm{cm} / \mathrm{s}), \mathrm{b})$ north velocities $(\mathrm{cm} / \mathrm{s})$ and c) EKE $\left((\mathrm{cm} / \mathrm{s})^{2}\right)$. In each case, we have averaged over the box data of Figures 5 and 6. Standard deviations are plotted as error bars. 

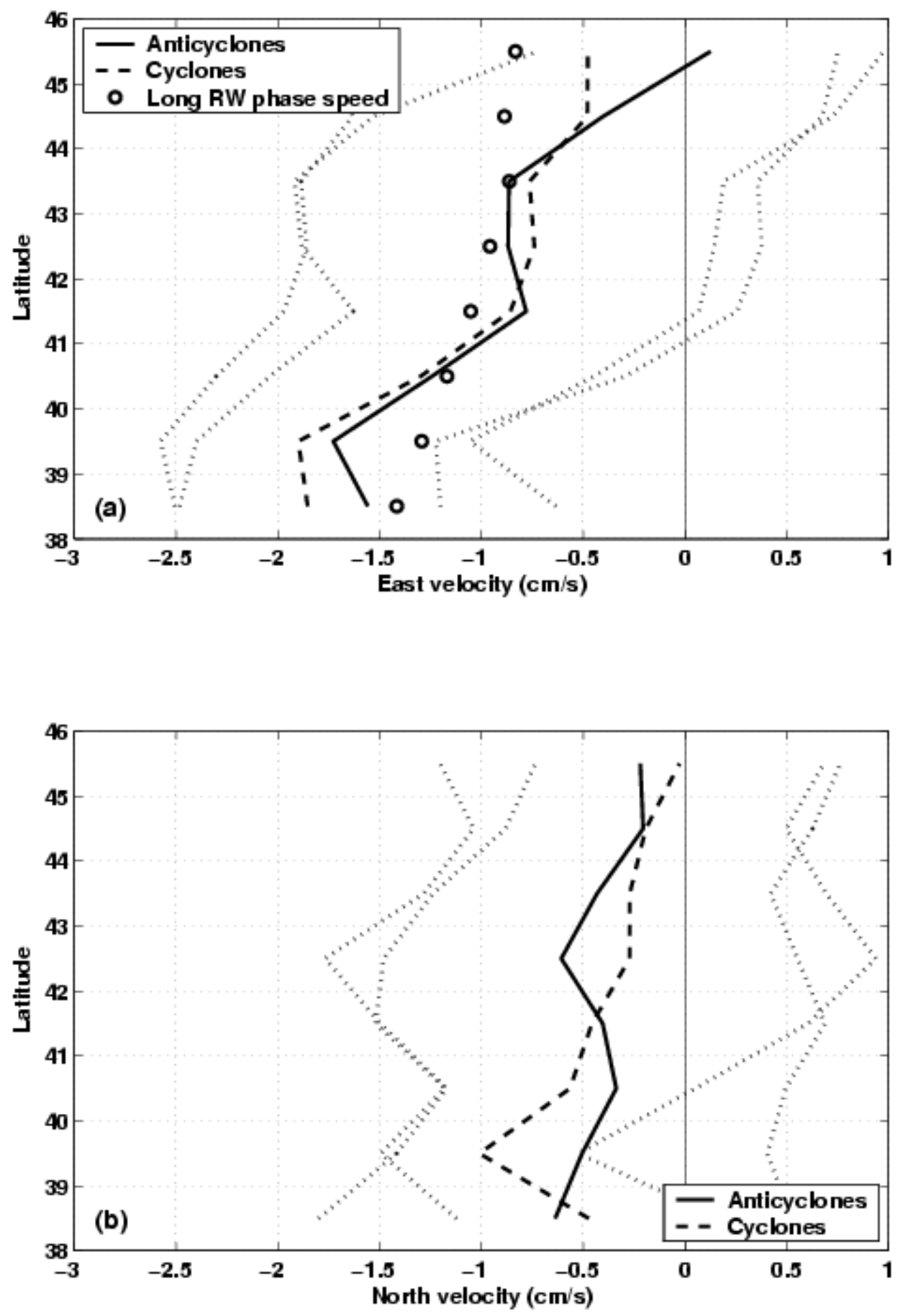

Figure 15

Eddy centers velocities computed from the combined altimetry-Lagrangian analysis (see text), as a function of latitude, for the period September 2000 - September 2001. a) East velocities of anticyclone (solid) and cyclone (dashed) centers ( $\mathrm{cm} / \mathrm{s})$. b) North velocities of anticyclone (solid) and cyclone (dashed) centers $(\mathrm{cm} / \mathrm{s})$. Velocities were averaged over $2^{\circ}$ latitude bands. Standard deviations are plotted as dotted lines. In a), the open circles indicate the mean phase speed of long
Rossby
Waves
as computed
by
Chelton
et al.
[1998]

(http://www.coas.oregonstate.edu/research/po/research/chelton/), in $1^{\circ}$ latitude x $1^{\circ}$ longitude boxes over the longitude band $13^{\circ}-23^{\circ} \mathrm{W}$. 